\title{
CEsifo \\ WORKING

\section{Working From Home: Too Much of a Good Thing?}

Kristian Behrens, Sergey Kichko, Jacques-François Thisse 


\section{Impressum:}

CESifo Working Papers

ISSN 2364-1428 (electronic version)

Publisher and distributor: Munich Society for the Promotion of Economic Research - CESifo

$\mathrm{GmbH}$

The international platform of Ludwigs-Maximilians University's Center for Economic Studies and the ifo Institute

Poschingerstr. 5, 81679 Munich, Germany

Telephone +49 (0)89 2180-2740, Telefax+49 (0)89 2180-17845, email office@cesifo.de

Editor: Clemens Fuest

https://www.cesifo.org/en/wp

An electronic version of the paper may be downloaded

- from the SSRN website: www.SSRN.com

- from the RePEc website: $\quad$ www.RePEc.org

- from the CESifo website: https://www.cesifo.org/en/wp 


\title{
Working From Home: Too Much of a Good Thing?
}

\begin{abstract}
We develop a general equilibrium model with three primary production factors-land, skilled, and unskilled labor - and three sectors - construction, intermediate inputs, and final consumption-to study how different intensities of telecommuting affect the efficiency of firms that embrace home working, as well as its impact on the whole economy. In doing so, we pay particular attention to the effects of increasing working from home (WFH) that go through changes in the production and consumption of buildings: more WFH reduces firms' demands for office space, but increases workers' demand for living space since additional room is required to work from home. We find that more WFH is a mixed blessing: the relationship between telecommuting and productivity or GDP is $\cap$-shaped, whereas telecommuting raises income inequality. Hence, WFH is not a panacea since an excessive downscaling of workspaces may be damaging to all and exacerbate economic inequality.
\end{abstract}

JEL-Codes: J200, R130, R140.

Keywords: working from home, alternative work arrangements, telecommuting, housing and office markets, land.

\author{
Kristian Behrens \\ Department of Economics \\ Université du Québec / Montréal / Canada \\ behrens.kristian@uqam.ca \\ Sergey Kichko \\ HSE University \\ Russia - 190068, Saint-Petersburg \\ sergey.kichko@gmail.com \\ Jacques-François Thisse \\ CORE-UCLouvain \\ Louvain-la-Neuve / Belgium \\ jacques.thisse@uclouvain.be
}

January 11, 2021

We thank J. Clapp, H. Koster, F. Mayneris, G. Mion, L. Taskin, and participants at several seminars for insightful comments and suggestions. 


\section{Introduction}

Recent empirical evidence shows that firms experience new organizations of labor in which the flexibility in 'where the work can be done' is a major feature (Spreitzer et al., 2017; Mas and Pallais, 2020), a trend that is being exacerbated by the Covid-19. According to its proponents, telecommuting, also called working from home (WFH) or telework-defined as work tasks performed from home or satellite offices once or several days per week - cuts commuting time and costs, reduces traffic congestion and the emission of greenhouse gases, and contributes to a better work-life balance. Furthermore, saving money on office space is key to firms or establishments in large cities where office rents have skyrocketed. However, it is fair to say that not much is known about the economic implications of WFH because the penetration rate of telecommuting was low until the numerous lock-downs caused by Covid-19. Since widespread telecommuting may become a permanent feature of the economic landscape, our societies might be subjected to a systemic shock whose consequences are still unclear. The core goal of this paper is to study how different intensities of telecommuting affect the efficiency of firms that embrace home working, as well as its impact on the whole economy. To preview our key findings, we find that telecommuting is a mixed blessing: the relationship between telecommuting and productivity or GDP is $\cap$-shaped. Hence, an excessive downscaling of workspaces may be damaging to all and exacerbate economic inequality.

The implementation of WFH is a multidimensional problem. The first, and probably most controversial, issue is about the impact of WFH on workers' productivity. Following the pioneering work of Bloom et al. (2015) who undertake a field experiment in a Chinese company, the economics literature leans towards a positive answer because WFH would allow workers to better organize their various business and home tasks (Spreitzer et al., 2017; Mas and Pallais, 2020). But is this argument really compelling? After a nine-month experience with remote work, Bloom et al. (2015) observe that 50 percent of the remote workers opted to return to the office option. Only 35 percent of those who originally wanted to work from home took up the WFH option, a result that comes as a surprise if most workers are more productive - and, thereby, earn a higher income - and benefit from a better work-life balance. Using a Japanese survey that provides the percentage of an employee's productivity under WFH conditions relative to the same employee's productivity at the usual workplace, Morikawa (2020) finds that the productivity during June 2020 was only about 60 to 70 percent of what it is at the workplace in June 2019. However, the productivity drop is significantly lower for skilled workers and long-distance commuters. Using data from a survey of 2,500 US full-time workers earning more than $\$ 20,000$ per year in 2019, Bloom (2020) finds that 51 percent of the workers reported working home at an efficiency rate of 80 percent or more. Etheridge et al. (2020) also use individual data from the UK Household Longitudinal Survey and find that, on average, workers are approximately as productive when they work from home as before the pandemic. However, this average masks wide disparities across jobs and industries. 
To summarize, there is no consensus in the economics literature on the productivity effects of WFH. What is more, based on various case studies, the management and psychology literatures take a different stance by stressing the fact that workers' isolation may have negative effects on their productivity due to interference between work and family responsibilities and the lack of contacts with their co-workers (Taskin and Bridou, 2010; Rockmann and Pratt, 2015). If telecommuting were to generate substantial productivity gains, firms that employ large numbers of skilled workers would have adopted telecommuting on a large scale a long time ago. This is not what happened before the Covid-19 pandemic since about less than 5\% of the U.S. labor force worked home in 2019. In sum, the state-of-the-art is rather inconclusive, probably because the effects of WFH depend on the characteristics of occupations and industries (Adams-Prassl et al., 2020; Bartik et al., 2020). ${ }^{1}$ Consequently, we think it is reasonable to view home-workers and office-workers as imperfect substitutes.

What are the other economic fundamentals of a widespread shift to telecommuting? Obviously, commuting is key because office workers need to go to the office whereas home workers do not. Commuting is very time consuming. For example, in 2014, 139 million American workers have spent a collective 3.4 million years in commuting (The Washington Post, February 25, 2016). Per year, the opportunity cost of the time spent in commuting comes to three to six weeks of work for a typical New Yorker and, on average, to four weeks of work for a resident of Greater Paris. It is, therefore, no surprise that commuting costs account for a significant share of workers' expenses (Redding and Turner, 2015). Monte et al. (2018) show for the U.S. that reducing commuting costs by 12 percent from 1990 to 2010 gives rise to a welfare gain of 3.3 percent. What is more, travelling between home and the workplace is reported to be one of the most unpleasant activities in individuals' daily life (Kahneman et al., 2004).

Equally important, the existence of a wage premium that increases with the density of economic activity is empirically well documented (Duranton and Puga, 2020). There are various sources that explain why labor is more productive in larger cities, and they can be subsumed by the triad: sharing, matching, and learning (Duranton and Puga, 2004). Various econometric studies show that knowledge and information spillovers are very localized because they arise mainly through face-to-face contacts among skilled workers while workplace inclusion supports trust and contacts (Arzaghi and Henderson, 2008; Carlino and Kerr, 2015; Liu et al., 2018; Rosenthal and Strange, 2020). These agglomeration effects that drive central-city productivity may be negatively affected if the number of skilled who work in the business district shrinks significantly. Since telecommuters do not benefit from those various effects, the existence of agglomeration economies should therefore hold back telework (Koren and Peto, 2020).

\footnotetext{
${ }^{1}$ Individual productivity also varies subtly with team composition and experience. For example, it is challenging to integrate new workers into existing teams as the former do not have access to the same common tacit-knowledgepool as the incumbents.
} 
WFH characterizes predominantly the skilled workers and thus is likely to have substantial distributional impacts. Dingel and Neiman (2020) observe that the 37 percent of US jobs that can be performed at home pay more than those that have to be performed in the workplace. KrantzKent (2019) documents that college-educated workers and those in managerial and professional occupations are more likely to work home than the population as a whole. Adams-Prassl et al. (2020) also find that workers with a university degree can do a significantly higher share of their work tasks from home. Similarly, Mattana et al. (2020) observe that in Denmark the Covid-19 has a strong negative impact on individuals with low education or vocational training, probably because their jobs are not portable. According to employers surveyed by Bartik et al. (2020), there seems to be less productivity loss from remote working in the case of educated and well-paid workers.s Therefore, it is important to distinguish between high-skilled and low-skilled workers because the former can telecommute much more easily than the latter.

Last, another important consequence of the growth of telecommuting is the possible re-shaping of large cities. After decades of flight to the suburbs, city centers have again become desirable places where to live. This trend is partly rooted in the shift toward a knowledge-based economy and is embodied in an expanding class of highly-educated and young professionals who work for high-tech, multinational firms, or finance, insurance, and real estate (FIRE). These workers spend a large number of hours at their jobs, which explains their growing distaste for commuting to the workplace and to the amenities they consume (Edlund et al., 2015; Couture and Handbury, 2020). This has fostered the emergence of a wide range of business-to-consumer activities supplied in city centers and produced by low-pay workers. Bloom (2020) predicts that WFH could remove up to 50 percent of spending in city centers. In other words, WFH could decrease substantially the number of employees in bars, restaurants, and shops. For centuries, modern economies have been urban economies. How the departure of highly-skilled jobs from cities may reshape the geography of cities - from the size and location of business centers to the sustainability and form of public transit - is thus a key issue, the importance of which goes way beyond the realm of urban economics.

By its very nature, telecommuting is bound to have profound effects on both labor and housing markets. Indeed, wired workers need more space at home to accomplish their tasks (which affects location choices and the residential construction sector), while firms' space requirements are strongly reduced (which also affects location choices and the office construction sector). As a result, the markets for land and buildings must occupy center stage in a work that aims to assess the global effects of telework on urban economies. It should, therefore, be clear that studying how the above effects interact to shape the economy requires a general equilibrium setting. Given the central role of the land and building markets, we also need to get a better understanding of how locales with different land and building supply elasticities are likely to be affected differently.

In this paper, we develop a full-fledged general equilibrium model with three primary production 
factors - land, skilled, and unskilled labor - and three sectors - the construction sector that supplies buildings to firms and workers, and the intermediate sector that supplies an endogenous range of intermediate inputs to the final sector, which itself produces the consumption good. ${ }^{2}$ Skilled workers benefit from spillovers when they interact in the office but bear commuting costs; while home workers save on commuting costs yet do not benefit from agglomeration economies and incur extra costs as they need to consume some residential space as office space. Skilled workers can work a varying share of their time in the office and the remaining share at home. More WFH leads to a trade-off between lower productivity and less costly office space at the firm level. The aggregate effects depend on how productivity changes - firms disregard externalities in making their choices of work arrangements - and on the interactions between labor and housing markets.

Our key results can be summarized as follows. First, it is profit-maximizing for firms to implement a partial WFH strategy, that is, the working time is split between home and office, which is beneficial to both the skilled and unskilled. Second, WFH is a mixed blessing: when the WFH share steadily increases, more telecommuting increases skilled and unskilled workers' productivity and GDP when there is no excessive downscaling of office space, whereas its starts to decrease productivity and GDP beyond some threshold. Indeed, because home-workers and officeworkers are imperfect substitutes, an increasing but small share of home-workers allows one to exploit more intensively the potential of the information and communication technologies (ICTs). However, beyond some level, a higher share of home-workers becomes less efficient for the current development of ICTs. In addition, a smaller share of office-workers reduces the strength of the knowledge and information spillovers which, therefore, do not produce desirable effects. In the same vein, there is first more and, then, less diversity in the intermediate sector. Assuming that the number of intermediate firms reflects the efficiency of the innovation system as in RomerGrossman-Helpman endogenous growth models, the foregoing result suggests that too much WFH may be detrimental to long-run innovation and growth via foregone agglomeration economies due to face-to-face contact and knowledge spillovers. Interestingly, these results confirm what OECD (2020) suggests in its recent report on the possible long-run consequences of increased telework.

Third, though it is desirable to implement an intermediate WFH share, we do not know where the top of the bell is. Some back-of-the-envelope computations using consensus parameter values suggest the WFH share that maximizes GDP varies between 20 and 40 percent (one or two working days per 5-day week). This is in broadly in line with recommendations made in human re-

\footnotetext{
${ }^{2}$ If the literature in management and psychology devoted to telecommuting is vast, the economics literature is relatively meager. While there are a number of empirical contributions that study the impact of telecommuting on productivity, theoretical papers are few. Safirova (2002) and Rhee (2008) are exceptions. The former author extends the monocentric city model to account for telecommuting when home workers and office workers are imperfect substitutes. However, Safirova (2002) remains within standard urban economics by considering a land market and a single sector producing the consumption good. Moreover, she provides only numerical solutions. Rhee (2008) studies the trade-off between working time and leisure and shows that most of the commute time saved by WFH is allocated to work rather than leisure.
} 
source management (see, e.g., Gajendran and Harrison, 2007). Fourth, whether WFH has positive or negative consequences for workers depends on the interplay between the WFH share and the efficiency of information and communication technologies: when those technologies are not very efficient, workers are better off when the WFH share remains relatively small. This may explain why WFH has not yet been implemented on a large scale. Last, if firms choose non-cooperatively how much to disperse their jobs, the equilibrium WFH share is larger than the one that maximizes the GDP. This is because firms disregard the positive externality that a larger number of intermediates has on the consumption sector.

The foregoing results are obtained under the assumptions of fungible land, that is, land can be used indifferently for housing or commercial purposes; and full adjustment of all building markets. While this might be reasonable in the long run, it is not in the short run due to the presence of rigidities in land and real estate markets. More specifically, work dispersion implies an oversupply of office space because some offices are unoccupied. In the short run, this extra supply is withdrawn from the market by their owners, for otherwise the building price would be driven down to zero. It is also reasonable to consider that the intermediate sector cannot produce a wider range of intermediates in the short run because new R\&D investments are required. In this case, the differences between the long-run and short-run effects of a rising WFH share are striking: whereas the former are bell-shaped, the latter are monotone. To be precise, building and land prices rise, unskilled income falls while skilled income increases. As to GDP, it slowly increases. Hence, the short-run benefits may send inappropriate signals about the long-run effects of WFH.

Turning to land markets, as telecommuting implies a significant reorganization of the buildings market, it should be clear that the availability of land matters. Indeed, a more elastic land supply is beneficial to the skilled and unskilled workers, while all sectoral outputs and GDP grow. In other words, the aggregate effects of WFH are stronger - especially for welfare and GDP - if the supply of land is more elastic. They are also stronger when there are less zoning restrictions or use-specific upfront investments (decontamination, infrastructures) that limit the redeployment of land from residential to commercial purposes. In the presence of frictions to the conversion of land, GDP decreases because more resources are used by the housing sector to produce the same amount of output. Yet, our general conclusions on the effects of WFH on welfare and inequality remain unchanged. To summarize, WFH and the shifting demand of residential and office space are likely to have the largest effects in cities with weak land-use regulations. This provides a neat and simple general equilibrium foundation to various works, such as Hilber and Vermeulen (2014), Turner et al. (2014), Cheshire et al. (2015), and Hsieh and Moretti (2019), which report that excessive land use regulation is damaging to the economy at a time where the WFH share was small.

The remainder of the paper is organized as follows. The model is presented in Section 2, with a special attention to the intermediate sector that implements the alternative work arrangements. 
In Section 3, we prove the existence and uniqueness of an equilibrium. Section 4 is devoted to the various implications of telecommuting for the three sectors, the two groups of workers, and GDP. Since adjustments in residential and office building demands are critical - as firms and workers may revise their real estate consumption with the WFH share - we consider the effects of rigidities in those markets in Section 5. In Section 6, we discuss how the global availability of land and imperfect substitutability between alternative uses influences the effects that telecommuting has in the whole economy. In Section 7 we discuss the equilibrium WFH share chosen by firms, while Section 8 concludes.

\section{The model and preliminary results}

We consider an economy that produces three goods: (i) a homogeneous consumption good, $x$; (ii) a differentiated intermediate input, $q(i)$, used to produce $x$; and (iii) buildings $B$. The intermediate sector operates under monopolistic competition and increasing returns, while the other two sectors produce under perfect competition and constant returns. Buildings are consumed as either housing by workers or as inputs - plants and offices - by the intermediate and final sectors. There are three primary production factors - land $S$, skilled labor $s$ (e.g., management, professional, and related occupations) and unskilled labor $\ell$ (e.g., construction workers, assembly-line workers). The city is divided into two areas, that is, a residential district where all workers live, and a business district where all production takes place. Moving between the two districts is costly but moving within a district is costless. Land is used as an input by the construction sector only and is owned by landowners. Since firms and workers do not choose their locations, there is only one price for land. Shipping the consumption good from the business district to the residential district is costless, so that its price in the same in the two districts. The consumption good is chosen as the numéraire, and thus its price $p_{x}$ equals 1 .

\subsection{Consumers}

The population is formed by workers and landowners. The mass of $k$-workers is given by $L_{k}$ for $k=\ell, s$. We assume that $L_{\ell}>L_{s}$. Each $k$-worker supplies inelastically one unit of her type of labor and consumes $h_{k}$ units of housing and $x_{k}$ units of the consumption good. Furthermore, land belongs to a given population of landowners.

\subsubsection{Skilled workers}

Skilled workers can work home (telecommuting) or in the office (commuting). The standard efficiency wage model can be used to show that workers make trade-offs between leisure time at home and effort in the workplace (Zenou, 2009). The empirical evidence confirms that individuals who 
have a longer commute are more prone to being absent from work, to arrive late at the workplace and/or to make less work effort (van Ommeren and Gutiérrez-i-Puigarnau, 2011). Following the urban economics literature, we model commuting costs using an iceberg $\tau_{k} \geq 1$, which amounts to lowering the worker's income. ${ }^{3}$ Since the opportunity cost of time increases with income (Small, 2012; Koster and Koster, 2015), it is reasonable to assume that $\tau_{s}>\tau_{\ell}$. Without loss of generality, we normalize $\tau_{\ell}$ to 1 and set $\tau_{s} \equiv \tau>1$.

When a skilled works home, she provides one efficiency unit of home-work; when she commutes to the firm, she provides $1 / \tau<1$ efficiency units of office-work. Therefore, commuting reduces workers' income through a depreciation of the efficiency units. Commuting thus is a pure social loss because it reduces the supply of efficiency units of office-work. This loss increases with $\tau$. Here lies the main social force that pushes toward telecommuting. We will see below that other forces also affect the desirability of home-working.

Furthermore, working at home requires additional space to perform professional tasks. As a result, a skilled worker must acquire a lot size which is larger than the housing space she uses for personal consumption. In other words, when a wired worker buys $h_{s}$ units of housing, $\bar{h} \geq 0$ units are used for professional purposes and $h_{s}-\bar{h}$ for private consumption. Hence, skilled workers have Stone-Geary preferences:

$$
U_{s}=\frac{1}{\gamma^{\gamma}(1-\gamma)^{1-\gamma}}\left(h_{s}-\bar{h}\right)^{\gamma} x_{s}^{1-\gamma},
$$

with $\gamma \in(0,1) .{ }^{4}$ Denoting the share of time spent in telecommuting by $\rho \in[0,1]$, we find it reasonable to suppose that $\bar{h}=\bar{h}(\rho)$ is an increasing function of $\rho$, with $\bar{h}(0)=0$.

Let $w_{s}$ be the wage paid to a skilled worker under the work arrangement $\rho \in[0,1]{ }^{5}$ Since her budget constraint is given by $p_{b} h_{s}+x_{s}=w_{s}$, where $p_{b}$ is the unit price of housing, maximizing (1) subject to that constraint yields the following demands for housing and the consumption good:

$$
h_{s}=\gamma \frac{w_{s}}{p_{b}}+(1-\gamma) \bar{h}, \quad \text { and } \quad x_{s}=(1-\gamma)\left(w_{s}-p_{b} \bar{h}\right)
$$

which both depend on $\bar{h}$. The foregoing expressions show that a skilled who works home buys a bigger lot size. However, she consumes a smaller quantity of the consumption good than a skilled who works in the office. Indeed, the housing consumption increases by an amount smaller than $\bar{h}$, while the quantity of housing used for personal consumption, $h_{s}-\bar{h}$, decreases with $\bar{h}$. In other

\footnotetext{
${ }^{3}$ According to BLS data (https://www.bls.gov/news.release/cesan.nr0.htm), Americans spent about 16-17\% of their income on transportation in 2019. This includes all expenses, not just commuting. Mas and Pallais (2017) find that American workers are willing to give up 8 percent of their wage for the option of WFH, thus suggesting that commuting likely represent a large share of the total transportation budget.

${ }^{4}$ Bloom (2020) finds that only 49 percent of respondents can work in a room other than their bedroom. Thus, in the long run, working from home requires additional space for professional tasks.

${ }^{5}$ Since demands are linear in income, we could view $\rho$ as the share of a firm's labor force that works home full time, whereas a share $1-\rho$ works full time at the office. Our results hold for such a type of work arrangement.
} 
words, a higher WFH share incentivizes the wired workers to buy more space but to consume less of it.

Plugging the demand functions (2) into (1) yields the indirect utility:

$$
V_{s}=\frac{w_{s}-p_{b} \bar{h}}{p_{b}^{\gamma}} .
$$

Note that $V_{s}$ decreases with $\bar{h}$. In other words, the direct effect of telecommuting is to reduce skilled workers' welfare because less housing space is available for private consumption.

\subsubsection{Unskilled workers}

We assume that the unskilled workers' activities must be undertaken within production facilities located in the business district. In other words, we have $\rho=0$, hence $\bar{h}=0$, so that unskilled workers' preferences are Cobb-Douglas:

$$
U_{\ell}=\frac{1}{\gamma^{\gamma}(1-\gamma)^{1-\gamma}} h_{\ell}^{\gamma} x_{\ell}^{1-\gamma}
$$

Since commuting costs for the unskilled are normalized to 1 , the unskilled wage $w_{\ell}$ is equal to the price of a unit of unskilled labor. As a result, unskilled workers' demands are given by

$$
h_{\ell}=\gamma \frac{w_{\ell}}{p_{b}}, \quad \text { and } \quad x_{\ell}=(1-\gamma) w_{\ell}
$$

Last, plugging the demand functions (5) into (4) yields the indirect utility:

$$
V_{\ell}=\frac{w_{\ell}}{p_{b}^{\gamma}}
$$

\subsubsection{Landowners}

Landowners' income is given by the total rent they collect from the construction sector that uses land as an input. Since landowners often account for a small share of the total population, we assume for simplicity that their housing consumption is negligible, so that landowners consume only the final good. Their aggregate demand for this good is therefore equal to the aggregate land rent $(A L R)$, which will be formally defined in sub-section 2.2.3.

\subsection{Production}

We next turn to the production side of the economy. 


\subsubsection{Buildings}

The demand for buildings stems from three types of buyers: (i) consumers; (ii) the final sector; and (iii) intermediate firms. Although housing, plants, and offices are different types of buildings, we assume for simplicity that they can be used equally by workers, the intermediate, and the final sectors, i.e., buildings are perfectly fungible. We discuss short-run frictions in the adjustment of buildings and land markets later in sections 5 and 6

According to Glaeser et al. (2005), the market for buildings is almost perfectly competitive. Following Combes et al. (2016), we assume that the production function for buildings is given by a Cobb-Douglas technology with land and unskilled labor production shares $\delta$ and $1-\delta$ : $B=\delta^{-\delta}(1-\delta)^{-(1-\delta)} S^{\delta} L_{b}^{1-\delta}$, where $B$ is the output of the construction sector, $S$ is the quantity of developed land, and $L_{b}$ is the total amount of unskilled labor employed in the construction sector. ${ }^{6}$ Hence, the marginal production cost equals

$$
c_{b}=r^{\delta} w_{\ell}^{1-\delta}
$$

where $r$ denotes the land rent. Even when the total amount of available land, $S$, is fixed, the total amount of buildings is endogenous because land and unskilled labor are substitutes. In particular, when demand for buildings, $B$, rises more workers are employed in the construction sector. The land rent is determined by the land market clearing condition:

$$
B \frac{\partial c_{b}}{\partial r}=S
$$

where $\partial c_{b} / \partial r$ is the amount of land required to produce one unit of building.

In what follows, we assume that the amount of land available for development increases with the output of the construction sector at a given elasticity $\mu \in[0,1]$, i.e., a higher demand for buildings allows more land to be developed:

$$
S=B^{\mu}
$$

where the total amount of developable land is supposed to be large enough for this quantity to be larger than or equal to the demand for land $S$ when $\mu=0$. A low value of $\mu$ means an inelastic land supply like in areas characterized by strong land-use regulations or difficult topography. A high value of $\mu$ means that the land supply is elastic, perhaps because there is still a large amount of undeveloped land or because land-use regulation is lax. In the limit, when $\mu=1$ the land supply is perfectly elastic. The value of $\mu$ reflects the scarcity of developable land (Saiz, 2010), the

\footnotetext{
${ }^{6}$ We could add capital to the model and assume that its supply is perfectly elastic at a given price determined in the national market. Doing so amounts to adding constant terms to the model and leaves our insights unchanged.
} 
restrictiveness of land use regulations (Glaeser et al., 2005), or both.

Equalizing (8) and (9) yields $\delta\left(w_{\ell} / r\right)^{1-\delta} B=B^{\mu}$, which can be solved for the equilibrium land rent as a function of the construction sector's output: ${ }^{7}$

$$
r=\delta^{\frac{1}{1-\delta}} w_{\ell} B^{\frac{1-\mu}{1-\delta}}
$$

Perfect competition in the construction sector implies that $p_{b}$ equals marginal cost:

$$
p_{b}=w_{\ell}^{1-\delta} r^{\delta}=\delta^{\frac{\delta}{1-\delta}} w_{\ell} B^{\frac{(1-\mu) \delta}{1-\delta}}
$$

Using this expression, we can compute the aggregate land rent that accrues to the landowners as follows:

$$
A L R=r S=\delta B p_{b}
$$

To sum up, both the price of buildings and the price of land increase with the output $B$ when $\mu<1$. By contrast, when the land supply is perfectly elastic $(\mu=1), p_{b}$ and $r$ are independent of $B$ because the demand for land is exactly matched by an increase in land supply.

When all buildings are perfectly fungible, we have $B=B_{h}+B_{x}+B_{I}$, where $B_{h}=L_{\ell} h_{\ell}+L_{s} h_{s}$ is the total housing demand, while $B_{x}$ and $B_{I}$ are the demands for buildings stemming from the final and intermediate sectors.

\subsubsection{Consumption good}

The final sector produces a homogeneous consumption good, $x$, under constant returns and perfect competition using buildings, a CES bundle of intermediate inputs, and unskilled labor. ${ }^{8}$ Specifically, the production function of this sector involves a Cobb-Douglas with nested CES technology:

$$
Y=\frac{1}{\alpha^{\alpha} \beta^{\beta}(1-\alpha-\beta)^{(1-\alpha-\beta)}} B_{x}^{\alpha} \mathbf{Q}^{\beta} L_{x}^{1-\alpha-\beta}, \quad \mathbf{Q} \equiv\left[\int_{0}^{M} q(i)^{\frac{\sigma-1}{\sigma}} \mathrm{d} i\right]^{\frac{\sigma}{\sigma-1}}
$$

In this expression, $Y$ is the total output of the consumption good, $B_{x}$ is the quantity of buildings used, $\mathbf{Q}$ is the CES aggregate of intermediate inputs, and $L_{x}$ is the total amount of unskilled labor employed in the final sector. In the CES aggregate, $q(i)$ is the quantity of intermediate input $i$, $\sigma>1$ is the elasticity of technological substitution between intermediates, and $M$ is the mass of inputs produced by the intermediate sector.

Given the above production function, the marginal production cost in the final sector is given

\footnotetext{
${ }^{7}$ From $(9),(10)$ is equivalent to $S(r)=\left[(1 / \delta)\left(r / w_{\ell}\right)^{1-\delta}\right]^{\mu /(1-\mu)}$, which is the land supply function. The latter increases with the land rent when $\mu \in(0,1)$ and its elasticity increases with $\mu$ (less land-use regulations).

${ }^{8}$ Our results remain valid if the final good is supplied as a continuum of horizontally differentiated CES varieties.
} 
by

$$
c_{x}=w_{\ell}^{1-\alpha-\beta} p_{b}^{\alpha} \mathbf{P}^{\beta}, \quad \text { where } \quad \mathbf{P}=\left[\int_{0}^{M} p(i)^{1-\sigma} \mathrm{d} i\right]^{\frac{1}{1-\sigma}}
$$

is the price index of intermediate inputs and $p(i)$ the price of variety $i$. Because of perfect competition and our choice of numéraire, we have $c_{x}=p_{x} \equiv 1$.

Note that there are increasing returns to scale in the final sector with respect to the range of intermediate goods. Indeed, assuming that $p(i)=p$ for all $i$ and holding expenditures on intermediates, $E_{I}=M p q$ fixed, the price index equals $\mathbf{P}=M^{\frac{1}{1-\sigma}} \frac{E_{I}}{M q}=M^{\frac{\sigma}{1-\sigma}} \frac{E_{I}}{q}$, thus showing that marginal cost $c_{x}=w_{\ell}^{1-\alpha-\beta} p_{b}^{\alpha}\left(E_{I} / q\right)^{\beta} M^{\frac{\beta \sigma}{1-\sigma}}$ is decreasing in the range of intermediates $M$.

\subsubsection{Intermediate inputs}

Turning to the intermediate sector, it produces a continuum of horizontally differentiated varieties using skilled labor, unskilled labor, and buildings. Each variety is supplied by a single firm. In line with trade and endogenous growth models, we assume that a firm hires skilled workers to design a particular intermediate input, called a variety. Afterwards, each firm produces that variety using unskilled labor and buildings.

Using (13), the total demand $q(i)$ for variety $i$ stemming from the final sector is given by

$$
q(i)=Y \frac{\partial c_{x}}{\partial p(i)}=\beta Y \mathbf{P}^{\sigma-1} p(i)^{-\sigma}
$$

Firm $i$ treats $Y$ and $\mathbf{P}$ parametrically because it is negligible in the sense that its actions have no impact on the market. Unskilled labor and buildings are combined using a Cobb-Douglas technology, so that the variable production cost of variety $i$ is given by: ${ }^{9}$

$$
V C_{I}(q(i))=w_{\ell}^{1-\alpha} p_{b}^{\alpha} q(i)
$$

Fixed costs. To design an intermediate input, a firm requires a fixed amount $F>0$ of efficiency units of skilled labor. Home- and office-work are imperfect substitutes in R\&D. When an intermediate firm hires $L_{I}$ skilled workers under the labor arrangement $\rho$, it secures $\rho L_{I}$ home-efficiency units of labor and $[(1-\rho) / \tau] L_{I}$ office-efficiency units, where $1 / \tau<1$ is the labor efficiency loss due to commuting to the office. We assume that combining $L_{h}=\rho L_{I}$ and $L_{o}=[(1-\rho) / \tau] L_{I}$ translates into $L_{h}^{\phi} L_{o}^{(1-\phi) \eta}$ efficiency units of skilled labor, with $\eta \geq 1$ and $\phi \in[0,1]$. In this expression, $\eta \geq 1$ measures the productivity gains due to the face-to-face contacts between office workers,

\footnotetext{
${ }^{9}$ For simplicity, we assume that the cost share of buildings, $\alpha$, is the same in the intermediate and final sectors. Our main results hold true when this share varies across sectors, but this comes at the cost of heavier formal expressions that are not especially illuminating. We further assume, without loss of generality, that units for the output of varieties are choosen for firms' total factor productivity to equal one.
} 
which allows for a better and faster dissemination of knowledge and information. The parameter $\phi \in[0,1]$ captures the level of development of the ICTs that allow individuals to work from home instead of commuting to and working at the firm. When all tasks must be performed under the same roof $\left(L_{h}=0\right)$, we have $\phi=0$ so that $\rho=0$. As the efficiency of ICTs grows, the value of $\phi$ increases, and thus firms increase their WFH share. At the limit, when $\phi=1$, there is full work dispersion $\left(L_{h}=L_{I}\right)$, i.e., all workers work where they live.

Since $F=\rho^{\phi}(1-\rho)^{\eta(1-\phi)} L_{I}^{\phi+\eta(1-\phi)} \tau^{-\eta(1-\phi)}$, given $\rho, \tau, \phi$, and $\eta$, an intermediate firm needs to hire a number of skilled workers $L_{I}$ given by

$$
L_{I}=\left[\frac{F \tau^{\eta(1-\phi)}}{\rho^{\phi}(1-\rho)^{\eta(1-\phi)}}\right]^{\frac{1}{\phi+\eta(1-\phi)}} .
$$

In the standard setting with integrated firms $(\phi=\rho=0), L_{I}$ is constant and equal to $\tau F^{1 / \eta}$. Otherwise, the value of $L_{I}$ varies with the work arrangement $\rho$. For any given $\phi \in(0,1)$, the denominator of $L_{I}$ equals 0 at $\rho=0$ and $\rho=1$ and is maximized at the interior value $\rho_{M} \equiv$ $\phi /[\phi+(1-\phi) \eta] \in(0,1)$ because $\eta \geq 1$ and $\phi \in(0,1)$. Hence, $L_{I}$ is a quasi-concave function of $\rho$. When ICTs improve $(\phi \uparrow)$, a firm needs a decreasing mass of efficiency units of labor to design a new variety because the firm benefits from more efficient ICTs. This holds even in the absence of spillovers $(\eta=1), \rho_{M}=\phi<1$. However, less efficient ICTs (low $\phi$ ) may not be sufficient to incite firms to disperse jobs because we disregard the transactions costs associated with a new organization of work within firms. Furthermore, higher commuting costs imply that a firm hires a larger number of skilled workers.

Since each firm requires $L_{I}$ units of skilled labor, the skilled labor market clears when the demand for skilled labor, $M \cdot L_{I}$, equals the supply, $L_{s}$. The equilibrium mass of intermediate firms, $M$, hence equals

$$
M=\frac{L_{s}}{L_{I}}=L_{s}\left[\frac{\rho^{\phi}(1-\rho)^{(1-\phi) \eta}}{F \tau^{\eta(1-\phi)}}\right]^{\frac{1}{\phi+(1-\phi) \eta}},
$$

which decreases with the fixed requirement $F$, like in the standard CES model of monopolistic competition, as well as with the level of commuting cost $\tau$ because each firm must hire more skilled workers. Since $L_{I} \rightarrow \infty$ for $\rho=0$ or 1 and is minimized at $\rho_{M}, M$ is a single-peaked function of $\rho$, which has a single maximizer $\rho_{M}$. This WFH share allows the final sector to reach its highest efficiency because of the increasing returns to scale we mentioned above. In sum, as $\rho$ steadily rises, the efficiency of the final sector follows a bell-shaped curve.

Turning to agglomeration economies in the intermediate sector, it is readily verified that the elasticity of $M$ with respect to $\eta$ is as follows:

$$
\mathcal{E}_{\eta}(M)=\frac{(1-\phi) \eta}{[\phi+(1-\phi) \eta]^{2}}\left[\phi \ln \frac{\rho}{\tau(1-\rho)}+\ln F\right] .
$$


Stronger spillovers $(\eta \uparrow)$ lead to a wider range of intermediate inputs if and only if $\rho<\rho_{I} \equiv$ $F^{1 / \phi} /\left(\tau+F^{1 / \phi}\right)<1$. Indeed, when the WFH share $\rho$ is small, a firm's pool of office-workers becomes more productive as spillovers get stronger. This in turn allows a firm to operate with a smaller mass $L_{I}$ of workers. By contrast, when $\rho>\rho_{I}$, the agglomeration force affects too small a pool of office-workers, which leads the firm to hire more workers. As a result, the mass of intermediate intermediate inputs decreases with $\eta$.

Production costs and profits. An intermediate firm requires one unit of office space for one skilled worker employed at the office. We also assume that skilled labor employed at home requires zero units of office space (from the firm's perspective). Therefore, office labor and office space are complements. An increase in $\rho$ thus allows an intermediate firm to reduce its space usage. For example, if workers come only 50 percent of the time to the office, they can share offices with others, which reduces the need for office space by half. This is especially important in locations commanding high rents, e.g., the downtowns of large cities or tech clusters. Since skilled workers are allocated with shares $1-\rho$ and $\rho$ to office work and to home work, the full price paid by the firm for one skilled worker equals $(1-\rho) p_{b}+w_{s}$. For given price $p_{b}$ and wage $w_{s}$, the fixed cost borne by the intermediate firm $i$ is thus given by

$$
F C_{I}=\left[(1-\rho) p_{b}+w_{s}\right] L_{I}=\left[(1-\rho) p_{b}+w_{s}\right]\left[\frac{F \tau^{\eta(1-\phi)}}{\rho^{\phi}(1-\rho)^{(1-\phi) \eta}}\right]^{\frac{1}{\phi+(1-\phi) \eta}}
$$

where we have used (17). Hence, the fixed cost decreases with the WFH share and increases with commuting costs. As a result, expensive office spaces naturally incentivize firms to decentralize their skilled jobs.

The total production cost of firm $i$ is given by

$$
C_{I}(i) \equiv V C_{I}(q(i))+F C_{I}=w_{\ell}^{1-\alpha} p_{b}^{\alpha} q(i)+\left[(1-\rho) p_{b}+w_{s}\right] L_{I}
$$

so that its profit function is as follows:

$$
\begin{aligned}
\pi_{I}(i) & =\left[p(i)-w_{\ell}^{1-\alpha} p_{b}^{\alpha}\right] q(i)-\left[(1-\rho) p_{b}+w_{s}\right] L_{I} \\
& =\left[p(i)-w_{\ell}^{1-\alpha} p_{b}^{\alpha}\right] \beta Y \mathbf{P}^{\sigma-1} p(i)^{-\sigma}-\left[(1-\rho) p_{b}+w_{s}\right] L_{I},
\end{aligned}
$$

where we have used (14). The profit function shows how firms can save on space to reduce their real estate costs.

Observe that firm $i$ 's operating profits and variable production costs are independent of $\rho$. Therefore, the profit-maximizing $\mathrm{WFH}$ share is the value $\rho^{*}$ that minimizes fixed costs. Since $L_{I}$ is strictly quasi-convex in $\rho$ while $(1-\rho) p_{b}+w_{s}$ decreases with $\rho, F C_{I}$ is also strictly quasi-convex 
and has a unique minimizer $\rho^{*}$, which is the same across firms. Differentiating $F C_{I}$ with respect to $\rho$ shows that $\rho^{*}$ is given by:

$$
\rho^{*}=\frac{\phi\left(p_{b}+w_{s}\right)}{\phi p_{b}+((1-\phi) \eta+\phi) w_{s}} \in(0,1] .
$$

Thus, for firms to choose full work dispersion, $\phi$ must be equal to 1 . Furthermore, $\rho^{*}$ decreases with the intensity of agglomeration economies, $\eta$. In other words, knowledge spillovers arising in the office put a break on work dispersion. Since the strength of spillovers varies across sectors (Faggio et al., 2017), the WFH share varies across sectors too (Bodenstein et al., 2020). Moreover, as countries are specialized in different sectors, it is not surprising that the WFH share also differs across countries (Gottlieb et al., 2020).

Price and firm size. Maximizing (19) with respect to $p(i)$, and noting that firms are symmetric, yields the equilibrium price set by intermediate firms

$$
p=\frac{\sigma}{\sigma-1} w_{\ell}^{1-\alpha} p_{b}^{\alpha}
$$

Thus, the price index of the intermediate sector equals

$$
\mathbf{P}=M^{\frac{1}{1-\sigma}} p=\frac{\sigma}{\sigma-1} M^{\frac{1}{1-\sigma}} w_{\ell}^{1-\alpha} p_{b}^{\alpha}
$$

Using (21) and (22) shows that operating profits are given by

$$
\Pi(p) \equiv\left(p-w_{\ell}^{1-\alpha} p_{b}^{\alpha}\right) \beta Y \mathbf{P}^{\sigma-1} p^{-\sigma}=\frac{\beta Y}{\sigma M}
$$

In line with trade and geography models, we assume that the skilled are the residual claimants, so that a firm's residual profits, $\Pi(p)-L_{I}(1-\rho) p_{b}$, are redistributed to these workers. Therefore, the equilibrium skilled wage $w_{s}$ solves the zero-profit condition:

$$
w_{s}=\frac{\beta Y}{\sigma L_{s}}-(1-\rho) p_{b},
$$

which increases with the WFH share. As shown in the next subsection, the equilibrium profits in the construction and final sectors are equal to zero because they operate under perfect competition and constant returns. Hence, total profits in the economy are equal to zero.

Furthermore, plugging (21) and (22) into (14) and using the market clearing condition for variety $i$ imply that firm $i$ 's equilibrium output is given by

$$
q=\frac{\sigma-1}{\sigma} w_{\ell}^{\alpha-1} p_{b}^{-\alpha} \frac{\beta Y}{M}
$$


Thus, as $\rho$ rises, the size of an intermediate firm decreases, reaches its minimum size at $\rho=\rho_{M}$ and, then, increases through the value of $M$. Note that (24) implies that the equilibrium size of an intermediate firm decreases with the unskilled wage, $w_{\ell}$, and with the price of buildings $p_{b}$. Finally, $q$ also increases with the fixed requirement of efficiency units of skilled labor, $F$, while a larger final sector (larger $Y$ ) leads to bigger intermediate firms.

Effects on the final sector. As explained before, there are increasing returns in the final sector as the range of intermediate goods increases. There are also agglomeration economies in the intermediate sector. How do the two interact to shape TFP? Since $\mathbf{Q}=M^{\frac{\sigma}{\sigma-1}} q$ at the equilibrium of the intermediate sector, the production function of the final sector becomes:

$$
Y=\frac{1}{\alpha^{\alpha} \beta^{\beta}(1-\alpha-\beta)^{(1-\alpha-\beta)}} M^{\frac{\beta \sigma}{\sigma-1}} B_{x}^{\alpha} q^{\beta} L_{x}^{1-\alpha-\beta}
$$

Observe that stronger spillovers within the office, measured by a higher $\eta$, translates into a more productive final sector through a wider range of varieties when $\rho<\rho_{I}$. Otherwise, a large work dispersion renders the final sector less productive through less variety in the intermediate sector. Its elasticity is equal to $\beta \sigma /(\sigma-1)>0$, which decreases with the elasticity of substitution $\sigma$ because varieties are closer substitutes whereas it increases with the share of intermediate inputs in producing the consumption good. Through the value of $M$, the TFP in the final sector is maximized at $\rho=\rho_{M} \in(0,1)$.

\section{The market outcome}

We now establish the equilibrium conditions and solve for the equilibrium of the model.

\subsection{The equilibrium conditions}

Unskilled labor. Recall that unskilled labor is used by all three sectors. Hence, the unskilled labor market clearing condition is given by $L_{\ell}=B \frac{\partial c_{b}}{\partial w_{\ell}}+Y \frac{\partial c_{x}}{\partial w_{\ell}}+M \frac{\partial V C_{I}}{\partial w_{\ell}}$. Using the cost functions $c_{x}, V C_{I}$, and $c_{b}$ defined previously yields:

$$
L_{\ell}=(1-\delta) r^{\delta} w_{\ell}^{-\delta} B+(1-\alpha-\beta) w_{\ell}^{-\alpha-\beta} p_{b}^{\alpha} \mathbf{P}^{\beta} Y+(1-\alpha) p_{b}^{\alpha} w_{\ell}^{-\alpha} M q
$$

By implication of (13), (23), (24), and (10), the market clearing condition for the unskilled can be rewritten as follows:

$$
w_{\ell} L_{\ell}=(1-\delta) B p_{b}+[(1-\alpha) \Upsilon-\beta] Y
$$

where $\Upsilon \equiv 1+\beta-\beta / \sigma>1$ is a bundle of parameters. 
Buildings. Using (13) and (18), we obtain the demand for buildings stemming from the final and intermediate sectors:

$$
B_{x}=Y \frac{\partial c_{x}}{\partial p_{b}}=\alpha Y \frac{w_{\ell}^{1-\alpha-\beta}}{p_{b}^{1-\alpha}} \mathbf{P}^{\beta}, \quad \text { and } \quad B_{I}=M \frac{\partial C_{I}}{\partial p_{b}}=M(1-\rho) L_{I}+\alpha M q\left(\frac{w_{\ell}}{p_{b}}\right)^{1-\alpha}
$$

Using (13), (17), and (24), these two expressions become:

$$
B_{x}=\frac{\alpha Y}{p_{b}}, \quad \text { and } \quad B_{I}=(1-\rho) L_{s}+\alpha \beta \frac{\sigma-1}{\sigma} \frac{Y}{p_{b}} .
$$

Market clearing in the construction sector implies $B=B_{h}+B_{I}+B_{x}$. Using (2), (5), and (26) yields the total output of the construction sector as follows:

$$
B=\underbrace{\gamma \frac{w_{\ell} L_{\ell}+w_{s} L_{s}}{p_{b}}+(1-\gamma) \bar{h} L_{s}}_{\text {residential demand }\left(B_{h}\right)}+\underbrace{\frac{\alpha Y}{p_{b}}+(1-\rho) L_{s}+\alpha \beta \frac{\sigma-1}{\sigma} \frac{Y}{p_{b}}}_{\text {commercial demand }\left(B_{I}+B_{x}\right)},
$$

where $(1-\gamma) \bar{h} L_{s}$ is the additional demand for housing generated by WFH, while $B_{o} \equiv(1-\rho) L_{s}$ is the demand for offices that stems from the intermediate firms.

Multiplying the foregoing expression by $p_{b}$, we obtain the total value of buildings:

$$
B p_{b}=\gamma\left(w_{\ell} L_{\ell}+w_{s} L_{s}\right)+\alpha \Upsilon Y+p_{b}[(1-\gamma) \bar{h}+1-\rho] L_{s}
$$

Consumption good. Plugging (22) into (13) and recalling that $p_{x} \equiv 1$, we obtain the following condition for profit maximization in the final sector:

$$
\left(\frac{\sigma}{\sigma-1}\right)^{\beta} M^{-\frac{\beta}{\sigma-1}} w_{\ell}^{1-\alpha(1+\beta)} p_{b}^{\alpha(1+\beta)}=1
$$

Using (2), (5), and (12), market clearing for the consumption good requires that:

$$
Y=(1-\gamma)\left[w_{\ell} L_{\ell}+\left(w_{s}-p_{b} \bar{h}\right) L_{s}\right]+\delta B p_{b}
$$




\subsection{Existence and uniqueness of an equilibrium}

We are now equipped to show that an equilibrium exists and is unique. The equilibrium system can be reduced to the following three equations in the three unknowns $B, w_{\ell}$, and $w_{s}$ :

$$
\begin{aligned}
\underbrace{B^{\frac{1-\delta \mu}{1-\delta}}}_{F(B)} & =\underbrace{(\bar{h}+1-\rho) \Omega L_{s} B^{\frac{(1-\mu) \delta}{1-\delta}}+\frac{\gamma+\alpha \Upsilon(1-\gamma)}{\delta^{\frac{\delta}{1-\delta}} \Psi} L_{\ell}}_{G(B)}, \\
1 & =\delta^{\frac{\alpha(1+\beta) \delta}{1-\delta}}\left(\frac{\sigma}{\sigma-1}\right)^{\beta} M^{-\frac{\beta}{\sigma-1}} B^{\alpha(1+\beta)(1-\mu) \frac{\delta}{1-\delta}} w_{\ell}, \\
\frac{w_{s}}{w_{\ell}} & =\frac{1-(1-\delta) \gamma}{(1-\delta) \gamma+\Gamma} \frac{L_{\ell}}{L_{s}}-\frac{\delta^{\frac{\delta}{1-\delta}} B^{\frac{(1-\mu) \delta}{1-\delta}}}{(1-\delta) \gamma+\Gamma}[(1-\delta)(1-\gamma) \bar{h}+(\Gamma+1-\delta)(1-\rho)],
\end{aligned}
$$

where

$$
\Psi \equiv \frac{(1-\delta) \gamma \beta}{\sigma}+(1-\alpha \delta) \Upsilon-\beta<1, \quad \Omega \equiv \frac{[(1-\alpha) \Upsilon-\beta](1-\gamma)}{\Psi}<1, \quad \Gamma \equiv(1-\alpha \delta)\left(\frac{\sigma}{\beta}+\sigma-1\right)-\sigma>1
$$

are positive bundles of parameters. Note that $\Upsilon, \Psi, \Omega$, and $\Gamma$ are independent of the parameters $\rho, \mu, \tau$, and $\phi$ used in our comparative statics analyses below.

Conditions (31) and (33) are obtained by plugging (11) and (30) into (25) and (28) and rearranging, whereas condition (32) is obtained by combining (11) and (29) and using (17). The equilibrium is obtained by solving a block diagonal system of equations. The first block is formed by equations (31)-(33), which can be solved recursively for $B, w_{\ell}$, and $w_{s}$. We first show that (31) has a unique positive solution, which is the equilibrium building output $B$. To this end, observe that $F(\cdot)$ is increasing and convex in $B$, while $G(\cdot)$ also increases with $B$ but can be either convex $((1-\mu) \delta>1-\delta)$ or concave $((1-\mu) \delta<1-\delta)$ in $B$. Furthermore, $F(0)=0$ and $G(0)>0$. Since the exponent of $B$ in $F(\cdot)$ is larger than that in $G(\cdot)$, equation (31) has a unique positive solution. Since a higher value of $\bar{h} \operatorname{shifts} G(B)$ upward, (31) implies that more buildings are produced when $\bar{h}$ increases. Second, substituting $B$ into (32) uniquely yields the equilibrium unskilled wage $w_{\ell}$. Expression (32) shows that $B$ and $w_{\ell}$ are inversely related: a higher unskilled wage leads to a smaller building output because of higher production costs. Last, substituting $B$ and $w_{\ell}$ into (33) yields the equilibrium skilled wage $w_{s}$ (as well as the skilled-unskilled wage ratio, the 'skill premium').

We show in Appendix A that the wage ratio exceeds 1, i.e., there is a skill premium, if the number of unskilled workers is large enough. From now on, we assume that this condition holds. Having obtained the equilibrium values of $B, w_{\ell}$, and $w_{s}$, we can retrieve the solutions of the second block of equations one by one. Plugging $B$ and $w_{\ell}$ into (11), we obtain the equilibrium price $p_{b}$ of buildings, while the equilibrium output $Y$ of the final sector can be obtained from (30) by substituting $p_{b}, w_{s}$ and $w_{\ell}$. Using $p_{b}, w_{\ell}$, and $Y$, the size of an intermediate firm is pinned down 
by (24), while the equilibrium price for intermediate varieties is given by (21). Last, we have seen that $M$ is given by (17).

We define a market equilibrium as a vector $\left(w_{s}, w_{\ell}, p_{b}, p, B, Y, q, M\right)$ that solves the conditions (21), (17), (24), (11) and (30)-(32). Since these equations have a unique solution, there exists a unique market equilibrium and this equilibrium displays a skill premium when the relative endowment of unskilled labor $L_{\ell} / L_{s}$ is sufficiently large.

\section{The bell-shaped curves in home-working}

We are now equipped to study the impact of our key parameters, the WFH share, $\rho$, and the elasticity of land supply, $\mu$, on the market outcome. How does WFH affect the equilibrium? How do these effects depend on the elasticity of land supply?

\subsection{The effects of WFH}

In this section, we determine how the main variables vary with a shock that shifts the economy towards a higher WFH share, $\rho$. To obtain clear-cut findings, it is convenient to use $\bar{h}(\rho)=k \rho^{\theta}$ with $\theta \in[0,1]$ and $0<k<1$. With that specification, $\bar{h}$ first increases fast when $\rho$ becomes positive because $h^{\prime}(0) \rightarrow \infty$, but rises at a decreasing rate as the worker's additional space needed for working expands less and less with the time spent home. We also assume that the elasticity $\theta$ is small because most of the additional space needed for working home is rent at the early stage of the process.

Building output. The first term on the right-hand side of (31) shifts upwards with $\rho$ when $\rho<\rho_{B} \equiv(k \theta)^{\frac{1}{1-\theta}}$ and, then, downward when $\rho>\rho_{B}$. Hence, for $\theta \in(0,1)$, the output of the construction sector first increases and, then, decreases with the WFH share. Hence, the city's physical size grows and then shrinks. This result highlights one of the main trade-offs associated with telecommuting: a rising share $\rho$ leads workers to buy more housing space, which pushes toward a higher output $B$, while firms purchase less office space, which pushes toward a smaller output $B$. The former effect overcomes the latter for $\rho<\rho_{B}$, the reason being that the increment in housing demand is high when $\rho$ is small (recall that $\bar{h}^{\prime}(0) \rightarrow \infty$ ). Once $\rho$ is large enough, the opposite holds true because the additional housing consumption is small, whereas firms keep using less commercial buildings. Disregarding workers' additional needs for housing overestimates the welfare gains expected from telecommuting and implies that the output of the construction

sector steadily decreases with the WFH share. Evaluating the full general equilibrium effect of telecommuting on the construction sector requires to consider that workers will demand more space in the long run to work from home. 
Taking the elasticity of (31) with respect to $\rho$, yields

$$
\mathcal{E}_{\rho}(B)=\frac{(1-\delta)\left(k \theta \rho^{\theta}-\rho\right) \Omega L_{s}}{(1-\delta \mu) B-(1-\mu) \delta\left(k \rho^{\theta}+1-\rho\right) \Omega L_{s}},
$$

where the denominator is positive because (31) implies $B>\left(k \rho^{\theta}+1-\rho\right) \Omega L_{s}$ while $1-\delta \mu>(1-\mu) \delta$. Thus, as seen above, $\mathcal{E}_{\rho}(B)>0$ if and only if $\rho<\rho_{B}$. Otherwise, the demand for buildings always decreases with the WFH share. In sum, $B$ is determined at the equilibrium of two opposite forces. When $\rho$ starts rising from 0 , the additional demand for housing overcomes the lower demand for office. However, when $\rho>\rho_{B}$, the latter effect dominates the former one.

In the plausible case where $\theta$ takes on a small value, $\rho_{B}$ is small. For example, when $\theta=0.05$ and $k=0.05$, we have $\rho_{B}=0.002$. In what follows, we assume without much loss of generality that $\rho>\rho_{B}$.

Mass of intermediate firms. Taking the elasticity of (17) with respect to $\rho$ yields

$$
\mathcal{E}_{\rho}(M)=\frac{\phi-[\phi+(1-\phi) \eta] \rho}{(1-\rho)(\phi+(1-\phi) \eta)},
$$

which is positive if $\rho<\rho_{M} \equiv \phi /[\phi+(1-\phi) \eta]$ and negative otherwise. As already explained, $a$ steady increase in home-working first leads to a growing mass of intermediate firms and, then, to its shrinking. While the demand for offices, $B_{o}=(1-\rho) L_{s}$, always decreases with $\rho$, a drop in office space is not sufficient to widen the range of intermediate inputs. This is because a higher skilled wage and/or a lower buildings supply may counterbalance the decrease in office demand.

In the absence of agglomeration economies in the office $(\eta=1)$, the mass of intermediate firms increases if $\rho<\phi$, and decreases otherwise. In any case, by reducing the fixed production cost of a new variety, WFH should foster a more diversified intermediate sector, which in turn makes the final sector more productive. Our results reveal the existence of a major trade-off between telecommuting and spillovers. This one is a close relative of the trade-off between agglomeration economies and commuting costs, which occupies center stage in urban economics (Duranton and Puga, 2020). The potentially detrimental effect of reducing face-to-face communication in the office has been recently emphasized during the Covid pandemic (Koren and Peto, 2020).

Wages. Computing the elasticity of the unskilled wage given by (32) with respect to $\rho$, we obtain the following expression:

$$
\mathcal{E}_{\rho}\left(w_{\ell}\right)=\frac{\beta}{\sigma-1} \mathcal{E}_{\rho}(M)-\frac{\alpha \delta}{1-\delta}(1+\beta)(1-\mu) \mathcal{E}_{\rho}(B) .
$$

First, recall that $M$ is bell-shaped. Second, $\mathcal{E}_{\rho}(B)$ is decreasing and finite while $\mathcal{E}_{\rho}(M) \rightarrow-\infty$ 
when $\rho \rightarrow 1$. Hence, there exists a unique threshold $\rho_{w_{\ell}}>\rho_{M}$ such that $\mathcal{E}_{\rho}\left(w_{\ell}\right)>0$ if $\rho<\rho_{w_{\ell}}$ while $\mathcal{E}_{\rho}\left(w_{\ell}\right)<0$ otherwise. Furthermore, we show in Appendix B that $w_{s} / w_{\ell}$ increases with $\rho$. In words, the wage ratio between the skilled and the unskilled rises with the WFH rate. Moreover, by definition we have $\mathcal{E}_{\rho}\left(w_{s}\right)=\mathcal{E}_{\rho}\left(w_{s} / w_{\ell}\right)+\mathcal{E}_{\rho}\left(w_{\ell}\right)$. Since the first term on the right-hand side is positive, there exists a threshold value $\rho_{w_{s}}>\rho_{w_{\ell}}$ such that $\mathcal{E}_{\rho}\left(w_{s}\right)>0$ if $\rho<\rho_{w_{s}}$ and $\mathcal{E}_{\rho}\left(w_{s}\right)<0$ otherwise.

Because the market for unskilled workers is perfectly competitive, they are paid at their marginal productivity (up to a constant markdown in the intermediate sector). By contrast, there is no traditional concept of 'marginal productivity' for the skilled workers because they are the residual claimants in the intermediate sector. However, we can consider that the marginal entrant's net operating profits, $\Pi(p)-(1-\rho) p_{b}$, measures the private value of the marginal variety. Hence, the wage $w_{s}$ paid by firms is proportional to the intermediate firm's net operating profit and, hence, to skilled workers' productivity.

To sum up, we have:

Proposition 1 (WFH and productivity) When the WFH share is not too large, a higher $\rho$ raises the productivity and wage of both skilled and unskilled workers. However, when the WFH share is sufficiently large, productivity and wage decrease with $\rho$ for both types of workers.

The intuition for the bell-shaped behavior of wages lies in the technology that combines homeand office workers. For simplicity, assume that $\eta=1$ so that $\rho_{M}=\phi$. In this case, when $\rho>\rho_{M}$, the efficiency of ICTs, captured by $\phi$, is too low to sustain a high share of tasks performed home: home work is not a good substitute for office work (on top of the foregone agglomeration economies). This generates a negative effect on the intermediate sector whose size shrinks. Combined with a decreasing demand for buildings, this leads to a lower demand for both skilled and unskilled workers, which, in turn, reduces their wages. By contrast, when ICTs becomes sufficiently efficient for $\phi$ to be large, the mass of firms in the intermediate sector increases over the interval $(0, \phi)$. As a result, both the skilled and unskilled wages increase because more varieties in the intermediate sector increase the productivity of the final sector. Hence, whether WFH has positive or negative consequences for both types of workers depends on the efficiency of ICTs in allowing skilled workers to efficiently design new inputs - and run firms - from home. Combining this result with the negative impact of $\rho$ on $M$ when $\rho$ is large shows that an excessive downscaling of office work is bad for productivity and for workers.

Land rent and the price of buildings. We now turn our attention to the impact of $\rho$ on the price of buildings and the land rent. Using (35), their elasticities are, respectively, given by

$\mathcal{E}_{\rho}(r)=\frac{\beta}{\sigma-1} \mathcal{E}_{\rho}(M)+\frac{1-\mu-\alpha \delta(1+\beta)}{1-\delta} \mathcal{E}_{\rho}(B), \quad$ and $\quad \mathcal{E}_{\rho}\left(p_{b}\right)=\frac{\beta}{\sigma-1} \mathcal{E}_{\rho}(M)+\delta \frac{1-\mu-\alpha(1+\beta)}{1-\delta} \mathcal{E}_{\rho}(B)$ 
The above expressions show that, for small values of $\rho$, both elasticities are positive because $\mathcal{E}_{\rho}(B)>0$ and $\mathcal{E}_{\rho}(M)>0$. On the other hand, when $\rho \rightarrow 1, \mathcal{E}_{\rho}(M) \rightarrow-\infty$ while $\mathcal{E}_{\rho}(B)$ is negative and finite, so that both elasticities are negative. Since $\mathcal{E}_{\rho}(M)$ changes sign only once while $\mathcal{E}_{\rho}(B)<0$, there exist two values $\rho_{p_{b}}$ and $\rho_{r}$ with $0<\rho_{p_{b}}<\rho_{r}<1$, such that: (i) $0<\mathcal{E}_{\rho}\left(p_{b}\right)<\mathcal{E}_{\rho}(r)$ if $\rho<\rho_{p_{b}}$; (ii) $\mathcal{E}_{\rho}\left(p_{b}\right)<0<\mathcal{E}_{\rho}(r)$ if $\rho \in\left(\rho_{p_{b}}, \rho_{r}\right)$; and (iii) $\mathcal{E}_{\rho}\left(p_{b}\right)<\mathcal{E}_{\rho}(r)<0$ if $\rho>\rho_{r}$. Furthermore, combining the above two expressions leads to the following relationship: $\mathcal{E}_{\rho}\left(p_{b}\right)=\mathcal{E}_{\rho}(r)-(1-\mu) \mathcal{E}_{\rho}(B)$. When $\mu<1$ and $\mathcal{E}_{\rho}(B)<0$, the building price reacts more to an increase in $\rho$ than the land rent. By contrast, we have $\mathcal{E}_{\rho}\left(p_{b}\right)=\mathcal{E}_{\rho}(r)$ when $\mu=1$. In other words, both building price and land rent are equally affected if and only if the land supply is perfectly elastic; otherwise $r$ changes faster than $p_{b}$.

The following proposition provides a summary of the foregoing results:

Proposition 2 (WFH, building price, and land rent) When the WFH share starts rising from 0 , both the land rent and the building price increase. As $\rho$ keeps rising, the land rent decreases while the building price increases. Finally, for a sufficiently high $\rho$, both prices fall.

How does the aggregate land rent, $A L R$, change? Computing its elasticity yields $\mathcal{E}_{\rho}(A L R)=$ $\mathcal{E}_{\rho}(r)+\mu \mathcal{E}_{\rho}(B)$. Stated differently, the landowners benefit from WFH when telecommuting takes off, but their incomes start decreasing beyond some point. Since $\mathcal{E}_{\rho}(B)<0$ for $\rho>\rho_{B}$, the aggregate land rent varies less than the price of land. These effects are stronger when land is more elastically supplied (larger $\mu$ ). The reason is that a more elastic land supply translates into a larger housing supply, thereby increasing aggregate land rent (a quantity rather than a price effect).

Residential and commercial buildings. Since we know how the output of the construction sector varies with the WFH share, we can determine how this output is distributed between housing $\left(B_{h}\right)$ and the intermediate and final sectors' demand for commercial buildings $\left(B_{I}\right.$ and $\left.B_{x}\right)$. Observe first that

$$
B_{x}=\alpha \frac{Y}{p_{b}}, \quad \text { and } \quad B_{I}=\alpha \beta \frac{\sigma-1}{\sigma} \frac{Y}{p_{b}}+(1-\rho) L_{s},
$$

where $Y$ is the output of the final sector. Combining (23), (25), and (30), we get

$$
\frac{Y}{p_{b}}=\frac{L_{\ell}}{K_{1}}\left(\frac{1}{1-\delta}-\gamma\right) \delta^{-\frac{\delta}{1-\delta}} B^{-\frac{(1-\mu) \delta}{1-\delta}}-\frac{1-\gamma}{K_{1}}(1-\rho+\bar{h}) L_{s}
$$

where

$$
K_{1} \equiv 1-\frac{(1-\gamma) \beta}{\sigma}+\frac{\delta[(1-\alpha) \Upsilon-\beta]}{1-\delta}>0
$$

As $\rho>\rho_{B}$, (36) implies that $Y / p_{b}$ increases, and thus $B_{x}$ increases. Furthermore, using (2), 
(5), and (11), the housing output

$$
B_{h}=\left[\gamma \frac{w_{s}}{w_{\ell}} \delta^{-\frac{\delta}{1-\delta}} B^{-\frac{(1-\mu) \delta}{1-\delta}}+(1-\gamma) \bar{h}\right] L_{s}+\gamma \delta^{-\frac{\delta}{1-\delta}} B^{-\frac{(1-\mu) \delta}{1-\delta}} L_{\ell}
$$

also increases with $\rho$ because the wage ratio increases whereas $B$ decreases. Last, since $B$ decreases, the intermediate sector's demand for buildings, $B_{I}$, must decrease.

The impact of commuting costs. Since (31) does not involve $\tau$, the equilibrium output of the construction sector is independent of commuting costs. By contrast, the magnitudes $w_{s}, w_{\ell}$, $p_{b}$, and $Y$ depend on $\tau$ via $M$. More specifically, as $M$ decreases with $\tau$, it follows from (32) that $w_{\ell}$ decreases with $\tau$. The skilled wage $w_{s}$ also decreases with $\tau$ and does so at the same rate as $w_{\ell}$ because (33) does not involve $\tau$. Using (11) and (36) show that the equilibrium values of $p_{b}$ and $Y$ are proportional to the unskilled wage. Hence, both decrease with $\tau$. Note also that (10) implies that the $A L R$ decreases with commuting costs. Thus, the whole economy shrinks when commuting costs rise. It is, therefore, not surprising that some work dispersion is socially desirable.

\subsection{The distributional effects of WFH}

Changes in the organization of work are likely to trigger sizable macroeconomic effects and to have a large redistributional impact. Those have attracted substantial attention recently. We first consider the GDP change and, then, investigate the impact of $\rho$ on workers' welfare.

(i) The Gross Domestic Product (GDP) of the economy is given by the sum of unskilled wages, skilled wages, and the aggregate land rent. Formally, we have

$$
G D P=w_{\ell} L_{\ell}+w_{s} L_{s}+A L R
$$

Combining Propositions 1 and 2, there exists a threshold $\rho_{G D P}>\rho_{w_{\ell}}$ such that the GDP first increases for $\rho$ smaller than $\rho_{G D P}$ and, then, decreases. In other words, telecommuting boosts the economy when the WFH share is low but hurts the economy once the WFH share is high.

(ii) Since GDP provides only partial information about people's well-being, we turn our attention to the impact of the WFH share on individual welfare. Consider first the welfare of the unskilled. Substituting $p_{b}$, given by (11), into (6) and taking the elasticity of $V_{\ell}$ with respect to $\rho$ yields the following expressions:

$$
\mathcal{E}_{\rho}\left(V_{\ell}\right)=(1-\gamma) \mathcal{E}_{\rho}(M)-\frac{\delta[\gamma+\alpha(1+\beta)(1-\gamma)] \gamma(1-\mu)}{1-\delta} \mathcal{E}_{\rho}(B)
$$

Using the same argument as for (35), there exists a value $\rho_{V_{\ell}}$ such that $\rho_{w_{\ell}} \leq \rho_{V_{\ell}}<1$ and $V_{\ell}$ decreases with $\rho$ over $\left[\rho_{V_{\ell}}, 1\right]$. 
(iii) As for the welfare of the skilled, we show in Appendix $\mathrm{C}$ that there exists a threshold $\rho_{V_{s}}>\rho_{w_{s}}$ such that $V_{s}$ increases with $\rho$ on $\left(\rho_{B}, \rho_{V_{s}}\right)$ and decreases for $\rho>\rho_{V_{s}}$.

To summarize:

Proposition 3 (WFH, GDP, and welfare) When the WFH share increases, the GDP and the welfare of both types of workers first increase and, then, decrease.

Finally, using (6) and (33), we get

$$
\frac{V_{s}}{V_{\ell}}=\frac{1-(1-\delta) \gamma}{(1-\delta) \gamma+\Gamma} \frac{L_{\ell}}{L_{s}}-\frac{(1-\delta+\Gamma) \delta^{\frac{\delta}{1-\delta}}}{(1-\delta) \gamma+\Gamma}(\bar{h}+1-\rho) B^{\frac{(1-\mu) \delta}{1-\delta}}
$$

As implied by $(31),(\bar{h}+1-\rho) B^{\frac{(1-\mu) \delta}{1-\delta}}$ varies in the same way as $B$. Therefore, for $\rho>\rho_{B}$, the welfare ratio increases with the WFH share. In other words, telecommuting has implications for inequality on top of it effects on wages, an aspect that is often absent from the debate about its costs and benefits.

\subsection{Where are the tops of the bells?}

A recurrent theme of our analysis is the existence of bell-shaped relationships between the WFH share and most economic variables. What is important to policy makers and workers is where the bliss points are. For example, is GDP maximized for a large or small value of the WFH share? Does this value differ much from the thresholds that maximize the wages of the skilled and of the unskilled? How large is the welfare gap between skill groups?

We have provided some qualitative answers to these questions in the foregoing sections. We now provide quantitative answers. Computing different thresholds on $\rho$ requires giving specific values to the various parameters. For our results to be meaningful, we will use the following empirically relevant parameter values: $\sigma=1.5$ for the elasticity of substitution among inputs; ${ }^{10} \gamma=0.35$ for the housing share of income and $\delta=0.36$ for the land share in construction (Combes et al., 2019); ${ }^{11} \alpha=0.1$ for the building share in urban manufacturing and services (Brinkman et al., 2015; Karadi and Koren, 2017); $\beta=0.35$ for the share of intermediate inputs in manufacturing; ${ }^{12}$

\footnotetext{
${ }^{10}$ Miranda-Pinto (2020) finds an elasticity of substitution $\sigma \approx 0$ for intermediates in manufacturing and $\sigma \approx 1$ for services. Miranda-Pinto and Young (2020) show that the elasticity of substitution among intermediate inputs varies a lot across sectors.

${ }^{11}$ The value $\gamma=0.35$ is obtained by Combes et al. (2019) for France. Davis and Ortalo-Magné (2011) find $\gamma=0.24$ for the US. Either value can be used without affecting our main conclusions.

${ }^{12}$ The US input-output matrix shows that $63.7 \%$ of manufacturing products are used as an input by the private sector (comprising agriculture, mining, manufacturing, energy, construction, and services). The manufacturing sector alone uses $31.4 \%$ of manufacturing products as an input for production. In France, $64.82 \%$ of manufacturing products are used as an input by the private sector (comprising agriculture, mining, manufacturing, energy, construction, and services), while the manufacturing sector alone uses $37.35 \%$ of manufacturing products as an input for production.
} 
and $\eta=1.03$ for the elasticity of agglomeration economies (Combes et al., 2012). We also set $L_{s}=1$ and $L_{\ell}=7$, i.e., skilled workers are about 12.5 percent of the working population. ${ }^{13} \mathrm{We}$ set $\tau=1.087$, i.e., commuting costs are $8 \%$ of workers' wages. As for the remaining parameters, for which we lack empirical evidence, we set $\theta=0.05$ (the elasticity of $\bar{h}$ is small), $k=0.05$, and $F=1$. We will also consider alternative scenarios for $\mu$ and $\phi$ : an inelastic land supply $(\mu=0.7)$ and elastic land supply $(\mu=0.9)$; and less efficient communication technology $(\phi=0.2)$ and more efficient communication technology $(\phi=0.4)$.

Figure 1 depicts skilled- and unskilled incomes, $w_{s}$ and $w_{\ell}$; relative income $w_{s} / w_{\ell}$ and relative welfare, $V_{s} / V_{\ell}$; and building prices $p_{b}$ and GDP as a function of the WFH share $\rho$. We show both the cases with an elastic land supply $(\mu=0.9$, solid curve) and the case with a less elastic land supply ( $\mu=0.7$, dashed curve). Panels (a) and (b) show that, quite naturally, $w_{s}$ and $w_{\ell}$ are higher the more elastic is the land supply. As shown in panel (f), GDP is also increasing with the land supply elasticity, thereby highlighting the importance of less land-use regulations for productivity and wages. Naturally, panel (d) shows that building prices fall with the land supply elasticity.

Panel (a) shows that the skilled wage increases with the WFH share until $\rho=0.36$ in the case of an elastic land supply, whereas it increases until $\rho=0.41$ in the case of an inelastic land supply. For the unskilled, as shown in panel (b), the thresholds are much lower, around $\rho=0.2$ in both cases. Thus, increasing the WFH share from low levels initially benefits all workers, but benefits only the skilled for larger values. Last, for high values of $\rho$ both the skilled and the unskilled wages start to decrease.

Panel (d) shows that building prices increase until $\rho=0.19$ in both cases (more elastic land supply $\mu=0.9$; and less elastic land supply, $\mu=0.7)$.

Panel (f) shows that GDP first increases and then decreases with $\rho$. In the case of both an elastic land supply and a less elastic land supply it is maximized at $\rho=0.21$. Hence, for our baseline parameter values, GDP is maximized for WFH shares around 0.2 , which would correspond to 1 working day at home per 5-day week.

Last, panels (c) and (e) depict the relative income and welfare of the skilled. They show that skilled income and welfare are much more sensitive to changes in the WFH share $\rho$ than unskilled income and welfare. As shown, the skilled always benefit more than the unskilled from an increase in the WFH share. This is reflected in an income ratio $w_{s} / w_{\ell}$ and a welfare ratio $V_{s} / V_{\ell}$ that are always increasing in $\rho$. Observe that the skilled are also much more affected by a less elastic land supply, especially for small WFH shares. The intuition underlying this effect is that a low value of $\mu$ makes housing more expensive, which increases the cost of WFH substantially for the skilled, especially if that share is low. Renting a place with an additional room is costly, the more so the less the worker saves in commuting costs by doing so.

\footnotetext{
${ }^{13}$ Recall that our model does not account for business-to-consumer service providers, such as schools, hospitals, banks and insurances, and law firms, which use a high share of skilled workers.
} 
Figure 1: Equilibrium outcomes as a function of the WFH share $\rho$ for less good communication technology $\phi=0.2$ (we depict $\mu=0.9$, solid curve; $\mu=0.7$, dashed curve).

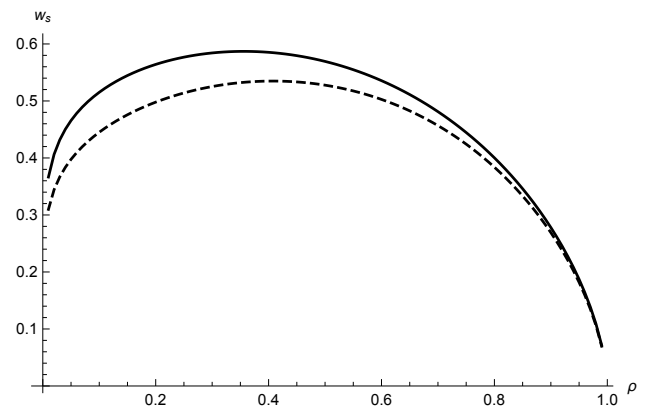

(a) skilled income, $w_{s}$

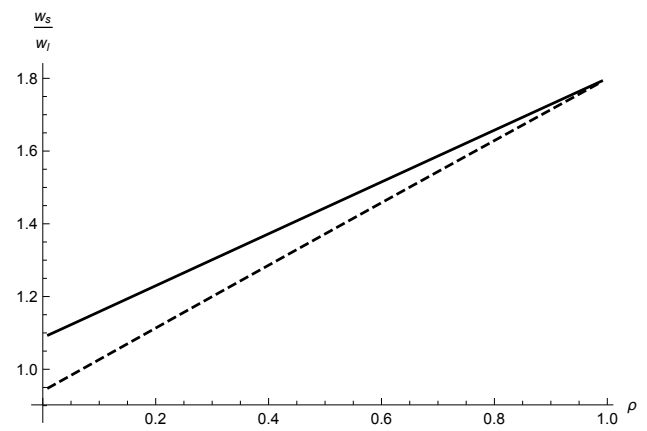

(c) relative income, $w_{s} / w_{\ell}$

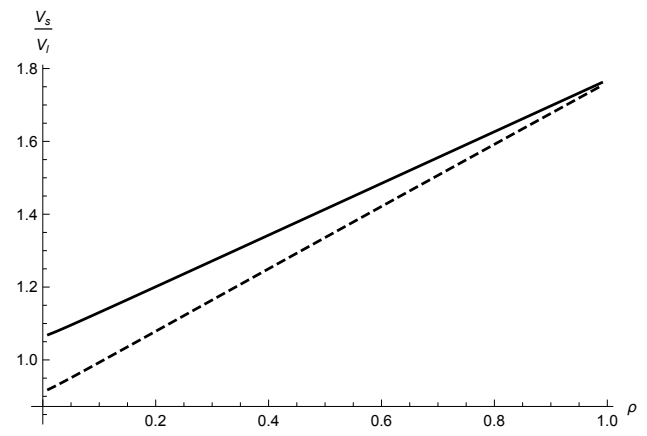

(e) relative welfare, $V_{s} / V_{\ell}$

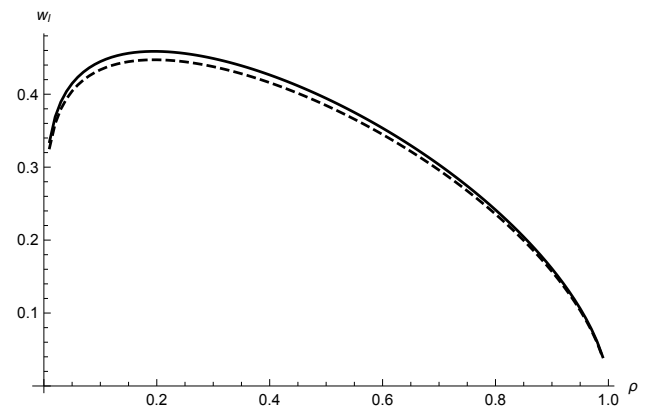

(b) unskilled income, $w_{\ell}$

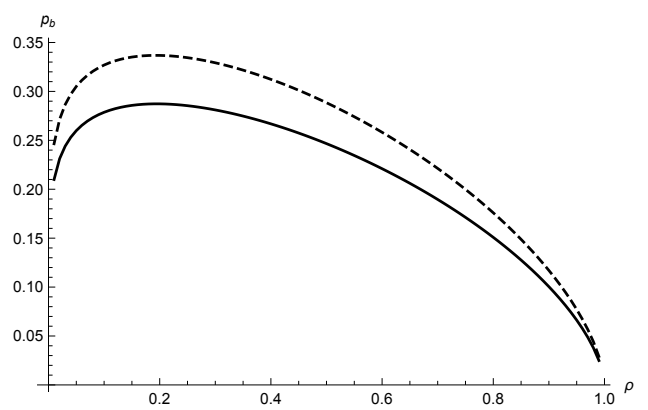

(d) building prices, $p_{b}$

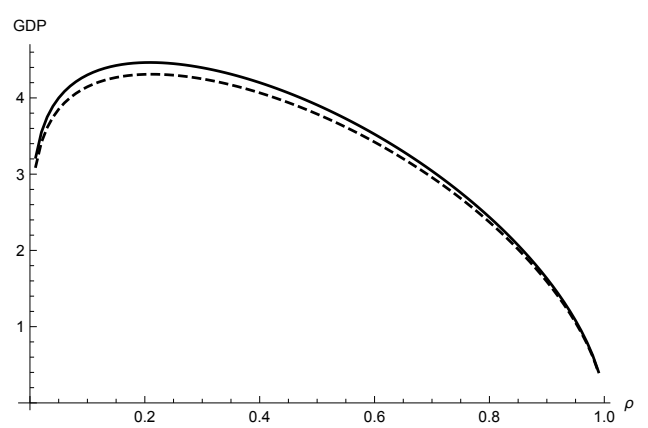

(f) Gross Domestic Product, GDP

Notes: The parameter values are set as follows: $\alpha=0.1, \beta=0.38, \delta=0.36, \gamma=0.35, \eta=1.03, \sigma=1.5, \theta=0.05, \mu=$ $\{0.7,0.9\}, L_{s}=1, L_{\ell}=7, \phi=0.2, k=0.05, \tau=1.087$, and $F=1$. 
To gauge the effects of land-use regulations on GDP, we compute the loss of GDP from moving from $\mu=0.9$ to $\mu=0.7$ for different value of $\rho$. When there is little WFH ( 5 percent) the GDP loss is 3.69 percent. For intermediate values of WFH (50 percent), the GDP loss is about 3.05 percent. Last, for high values of WFH (75 percent), the GDP loss is about 2.72 percent. Finally, note that too much WFH can have sizable costs in terms of economic output. Moving from a 5 percent WFH share to a 75 percent WFH share for the skilled would reduce GDP by about 30 to 31 percent in either the low or the high land supply elasticity case.

Figure 5 in Appendix $G$ depicts the same variables than in Figure 1, but with an improved communications technology $\phi=0.4$. As shown, most variables behave in a similar way than when $\phi=0.2$. However, better communication technologies lead to wider intervals over which wages and GDP increase with the WFH share. For instance, for an elastic land supply $(\mu=0.9)$, the GDP is maximized at around $\rho=0.2$ when $\phi=0.2$ whereas the maximum is reached at $\rho=0.41$ when $\phi=0.4$. Although more efficient ICTs permit to efficiently sustain larger WFH shares, we observe that GDP is lower for small WFH shares because the potential of advanced ICTs is underused. In other words, the adoption of new wired technologies need not be desirable when the WFH share is low. This coordination failure may explain why WFH was low before the Covid pandemic, even though the technology for sustaining larger shares probably existed. Only when a sufficiently large mass of intermediate firms move to a large $\rho$ can the new technology be implemented at efficient scale. The Covid shock may thus act as a coordination device and shift the economy to a new equilibrium (Bartik et al., 2020). Note that the percentage differences between the low and high land supply elasticity cases are about the same for $\phi=0.2$ and $\phi=0.4$.

\section{Market rigidities in the short run}

Thus far, we have assumed that all variables can adjust costlessly and that the skilled and unskilled wages are determined together with the mass of intermediate firms and the output of the three sectors (including housing). We view this exercise as one that traces out all the potential consequences of changes in home-work arrangements when all markets can adjust in the long run. However, we find it relevant from the policy standpoint to investigate the consequences of WFH in a short-run context where some variables are fixed due to various adjustment costs. More specifically, we assume that residential construction and the intermediate sector have not yet reacted to a change in $\rho$, i.e., the housing consumption $B_{h}$ and the mass of intermediate goods $M$ are fixed, so that $L_{I}$ is also fixed. We further assume that the office supply, given by $B_{o}=(1-\rho) L_{s}$, remains fixed in the short run. ${ }^{14}$ When $\rho$ rises, work dispersion implies an oversupply of offices as some commercial buildings become unoccupied. In what follows, we assume that this extra

\footnotetext{
${ }^{14}$ The demand of buildings from the intermediate sector, $B_{I}$, involves both office buildlingsand production facilities. The latter can be adjusted.
} 
supply is withdrawn from the market by their owners, for otherwise the buildings price would be driven down to zero. ${ }^{15}$ Our aim is here to determine how incomes, welfare, and GDP respond to an increase in the WFH share when $B_{h}=\bar{B}_{h}, B_{o}=\bar{B}_{o}$ and $M=\bar{M}$ are fixed.

Let $B_{p}$ denote the (variable) supply of buildings for production. Since the amounts of office space and residential buildings are given, (26) implies:

$$
B_{p}=\alpha \Upsilon \frac{Y}{p_{b}}
$$

while $B=\bar{B}_{h}+\bar{B}_{o}+B_{p}$ is the total building supply, which involves a fixed and a variable part.

Since housing consumption is fixed $\left(h_{s}=\bar{h}_{s}\right.$ and $\left.h_{\ell}=\bar{h}_{\ell}\right)$, workers' demands for the consumption good are given by $x_{k}=w_{k}-p_{b} \bar{h}_{k}$ for $k=\ell, s$. This implies that (30) must be replaced by the following condition:

$$
Y=w_{\ell} L_{\ell}+w_{s} L_{s}-\bar{B}_{h} p_{b}+\delta B p_{b}
$$

Combining (38) and (39) with (23) and using (11) leads to the following equation for $B$ :

$$
B^{\frac{1-\mu \delta}{1-\delta}}=K_{2}\left\{[(1-\alpha \Upsilon) \sigma-\beta] \bar{B}_{h}+(\sigma-\beta) \bar{B}_{o}-\alpha \Upsilon \sigma(1-\rho) L_{s}\right\} B^{\frac{(1-\mu) \delta}{1-\delta}}+\delta^{-\frac{\delta}{1-\delta}} K_{3} L_{\ell}
$$

where

$$
K_{2} \equiv \frac{1}{(1-\alpha \Upsilon \delta) \sigma-\beta}>0, \quad \text { and } \quad K_{3} \equiv \alpha \Upsilon \sigma K_{1}>0
$$

Note that (40) is the equivalent of (31) when $\bar{B}_{h}+\bar{B}_{o}$ are fixed. To be precise, conditional on $\bar{B}_{h}$ and $\bar{B}_{o}$, (40) pins down the equilibrium value of $B$ (or, equivalently, of $B_{p}$ ). When $\rho$ rises, the right-hand side of (40) shifts upward, so that $B_{p}$ increases with $\rho$, that is, $\mathcal{E}_{\rho}(B)>0$.

This may come as a surprise because the demand for offices $B_{o}=(1-\rho) L_{s}$ decreases due to the higher WFH share. However, we assume that the different types of building are not fungible in the short run. Therefore, while office spaces remain unoccupied, the expansion of the construction sector's output is due to the higher demand for production facilities.

In the short-run, the expansion of the construction sector is driven by a higher demand for production facilities, $B_{p}$. We will see below that a hike in demand for production facilities stems from a higher level of production of intermediate and final goods. This output expansion goes together with a demand for land, thus meaning that the physical size of the city grows with the WFH share.

Taking the elasticities of $(10)$ and $(11)$, and using $\mathcal{E}_{\rho}\left(w_{\ell}\right)$ given below, yields $\mathcal{E}_{\rho}\left(p_{b}\right)=(1-$ $\alpha(1+\beta))(1-\mu) \frac{\delta}{1-\delta} \mathcal{E}_{\rho}(B)>0$ and $\mathcal{E}_{\rho}(r)=(1-\alpha \delta(1+\beta))(1-\mu) \frac{\delta}{1-\delta} \mathcal{E}_{\rho}(B)>0$. Hence, the land

\footnotetext{
${ }^{15}$ For example, in 2018, Enfield Square Mall (Connecticut), which had 60 percent vacancy, was auctioned by the lender who acquired the property in 2017 . The auction fetched $\$ 10.85$ million for a property that sold 12 years earlier for $\$ 85$ million (we thank John Clapp for this information). Furthermore, in a dynamic context, the option value of housing rental could also explain non-zero prices despite the presence of unoccupied office spaces.
} 
rent and the price of buildings used to produce the intermediate and final goods increase, which is consistent with the expansion of the construction sector.

We now turn our attention to the impact of $\rho$ on wages. First, since $B_{p}$ increases, it follows from (38) that $Y / p_{b}$ also increases with $\rho$. As the zero-profit condition (23) may be rewritten as

$$
\frac{w_{s}}{p_{b}} L_{s}=\frac{\beta}{\sigma} \frac{Y}{p_{b}}-(1-\rho) L_{s},
$$

the ratio $w_{s} / p_{b}$ must increase with $\rho$. Second, since both $w_{s} / p_{b}$ and $p_{b}$ increase with $\rho, w_{s}$ must increase too. Third, using $(32)$ and recalling that $M$ is fixed, we obtain $\mathcal{E}_{\rho}\left(w_{\ell}\right)=-\alpha(1+\beta)(1-$ $\mu) \frac{\delta}{1-\delta} \mathcal{E}_{\rho}(B)<0$. Hence, the wage gap widens.

Consider next the effect of a rising WFH share on the outputs of the intermediate and final sectors. First, as $Y / p_{b}$ and $p_{b}$ increase with $\rho$, the output $Y$ of the final sector increases when there is more work dispersion. Second, as $\mathcal{E}_{\rho}\left(w_{\ell}^{1-\alpha} p_{b}^{\alpha}\right)=-\alpha \beta(1-\mu) \frac{\delta}{1-\delta} \mathcal{E}_{\rho}(B)<0$, the marginal production cost in the intermediate sector decreases with $\rho$. Since $Y$ increases while $M$ is fixed, it then follows from (24) that an intermediate firm's output $q$ increases, hence the total output $M q$ of the intermediate sector, rises with the WFH share. In sum, in the short-run the output of all sectors grows with $\rho$.

The short-run welfare effects of WFH are especially neat. First, the skilled pay a higher housing price and enjoy a smaller share of their place. At first sight, the skilled seem to be worse off. However, they earn a higher wage that allows them to consume a sufficiently large quantity of the consumption good for these workers to be better off. Indeed, since $V_{s}$ is proportional to $p_{b}^{1-\gamma}\left(w_{s} / p_{b}-\bar{h}_{s}\right), V_{s}$ increases because both $p_{b}$ and $w_{s} / p_{b}$ increase with $\rho$. Second, the unskilled are always worse off because $w_{\ell}$ decreases while $p_{b}$ increases. In other words, the short-run market rigidities imply that more work dispersion is detrimental to the unskilled, who are the only losers caused by the new work arrangements.

Finally, the impact of WFH on GDP is a priori ambiguous because both $w_{s} L_{s}$ and $A L R$ increase whereas $w_{\ell} L_{\ell}$ decreases. Figure 2 shows how the GDP changes in the short run. Starting from a WFH share of 5\% (panel a) and from a WFH share of 25\% (panel b) we see that in the former case the short-run adjustment understates the long-run changes when $\rho$ is smaller than 0.4 , whereas it overstates them otherwise. This suggests that moving from an initial long-run equilibrium with a low WFH $(\rho=0.05)$ to a new long-run equilibrium with substantial WFH $(\rho>0.4)$ would overestimate the changes in GDP if the full general equilibrium adjustment going through the housing market is not taken into account. This outcome is all the more likely if the initial long-run WFH share is large (see panel b).

To summarize, the differences between the long-run and short-run effects of a rising WFH share are striking: the former are mostly bell-shaped, whereas the latter are monotone increasing or decreasing. Hence, any assessment of work dispersion should pay attention not only to the 
Figure 2: Short-run (solid) versus long-run (dashed) changes in GDP.

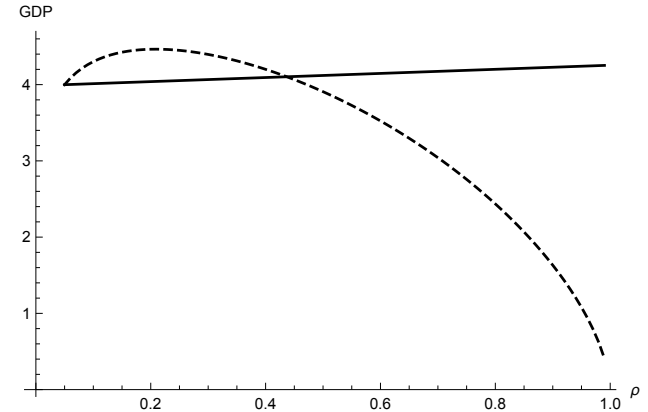

(a) starting from $\rho=0.05$

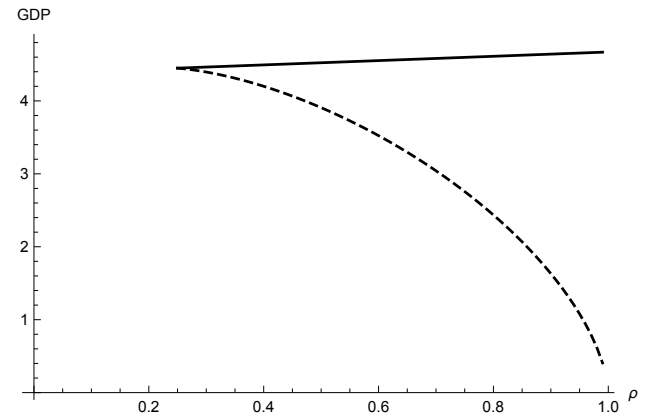

(b) starting from $\rho=0.25$

Notes: The parameter values are set as follows: $\alpha=0.1, \beta=0.38, \delta=0.36, \gamma=0.35, \eta=1.03, \sigma=1.5, \theta=0.05, \mu=$ $0.9, L_{s}=1, L_{\ell}=7, \phi=0.2, k=0.05, \tau=1.087$, and $F=1$.

short-run effects, but also it should account for the long-run effects when markets (especially the market for housing) can adjust to the new work arrangements, the reason being that the shortand long-run effects vastly differ when work dispersion is widely implemented.

\section{The land supply and the equilibrium WFH share}

The question of how land development and land-use regulations affect firms' productivity and workers' welfare occupies center stage in urban economics and city planning (Glaeser and Gyourko, 2018). This is why we find it relevant to investigate the aggregate impact of the land supply elasticity and frictions in the alternative uses of land on industries' outputs and workers' wellbeing in the presence of telecommuting. We then investigate the case where firms' decide on the WFH share $\rho$ by choosing it endogenously.

\subsection{Land supply elasticity}

For the elasticity of the land supply or frictions in the alternative uses to matter, the output of the construction sector must of course be endogenous. We, therefore, revert to the long-run setting where buildings are fungible and can be adjusted across all uses.

We start with the comparative statics with respect to the overall land supply elasticity, $\mu$. As in Saiz (2010), we may view lower values of $\mu$ as corresponding to a situation in which the supply of land is less elastic globally because of geographic features such as water, wetlands, or steep terrain. Using (31) leads to the following elasticity of the building output with respect to $\mu$ :

$$
\mathcal{E}_{\mu}(B)=\frac{\mu \delta}{\Lambda}\left[B-(\bar{h}+1-\rho) \Omega L_{s}\right] \ln B
$$

where $\Lambda \equiv(1-\mu \delta) B-(1-\mu) \delta(\bar{h}+1-\rho) \Omega L_{s}$. Since $B-(\bar{h}+1-\rho) \Omega L_{s}>0$ due to $(31)$, while 
$1-\mu \delta>(1-\mu) \delta$ implies $\Lambda>0$, we have $\mathcal{E}_{\mu}(B)>0$ if and only if $B>1$. We show in Appendix $\mathrm{E}$ that $B>1$ when $L_{\ell}$ is sufficiently large, so that $\ln B$ is positive. As a result, a more elastic land supply, e.g., less restrictive land-use regulations, leads to more built space.

We now look at the impact of $\mu$ on wages. Equation (33) may be rewritten as follows:

$$
\frac{\delta^{\frac{\delta}{1-\delta}}}{(1-\delta) \gamma+\Gamma}[(1-\delta)(1-\gamma) \bar{h}+(\Gamma+1-\delta)(1-\rho)] B^{\frac{(1-\mu) \delta}{1-\delta}}=\frac{1-(1-\delta) \gamma}{(1-\delta) \gamma+\Gamma} \frac{L_{\ell}}{L_{s}}-\frac{w_{s}}{w_{\ell}}
$$

Taking the elasticity with respect to $\mu$ and using (41), we obtain

$$
\mathcal{E}_{\mu}\left(\frac{w_{s}}{w_{\ell}}\right)=\frac{\mu \delta}{1-\delta} \frac{\frac{1-(1-\delta) \gamma}{(1-\delta) \gamma+\Gamma} \frac{L_{\ell}}{L_{s}}-\frac{w_{s}}{w_{\ell}}}{\frac{w_{s}}{w_{\ell}}} \frac{(1-\delta) B}{\Lambda} \ln B>0
$$

In other words, the wage ratio rises with $\mu$.

We now examine how wages vary with $\mu$. Using (32), we obtain:

$$
\mathcal{E}_{\mu}\left(w_{\ell}\right)=\frac{\alpha(1+\beta) \mu \delta B}{\Lambda} \ln B>0
$$

Since both the income ratio and the unskilled income increase, the skilled wage must increase with $\mu$. Moreover, it does so at a higher rate than $w_{\ell}$. In sum, a more elastic land supply increases both incomes but exacerbates inequality between workers.

We next use (10), (11) and (42) to uncover the impact of $\mu$ on building and land prices. Taking the elasticity of these two expressions yields:

$$
\mathcal{E}_{\mu}\left(p_{b}\right)=-\frac{\delta[1-\alpha(1+\beta)]}{\Lambda} \mu B \ln B<0 \quad \text { and } \quad \mathcal{E}_{\mu}(r)=\frac{1-\alpha \delta(1+\beta)}{\delta[1-\alpha(1+\beta)]} \mathcal{E}_{\mu}\left(p_{b}\right)<\mathcal{E}_{\mu}\left(p_{b}\right)
$$

where the second inequality holds because $\delta<1$. Landowners obviously want $\mu$ to be small, which gives rise to rent-seeking via lobbying for land-use regulations.

As to the output of the sectors, combining (25) and (30) leads to

$$
\left[\frac{1-\delta}{\delta}+(1-\alpha) \Upsilon-\beta\right] Y=w_{\ell} L_{\ell}+\frac{(1-\delta)(1-\gamma)}{\delta}\left[w_{\ell} L_{\ell}+\left(w_{s}-p_{b} \bar{h}\right) L_{s}\right]
$$

Therefore, the final sector produces more when $\mu$ is larger because both wages increase while $p_{b}$ decreases. Moreover, dividing the last equation by $w_{\ell}$ shows that $Y / w_{\ell}$ also increases since the wage ratio increases. Combining this with (24) shows that an intermediate firm's output, $q$, also increases with $\mu$ because the mass of intermediate firms $M$ is unaffected by $\mu$.

Furthermore, GDP can be expressed as follows

$$
G D P=Y+h_{s} L_{s}+h_{\ell} L_{\ell}=Y+\gamma\left(w_{\ell} L_{\ell}+w_{s} L_{s}\right)+(1-\gamma) p_{b} \bar{h} L_{s}
$$


where we use (2) and (5). The impact of $\mu$ on $G D P=w_{s} L_{s}+w_{\ell} L_{\ell}+\delta B p_{b}$ is thus generally unclear because both wages and $Y$ increase while $p_{b}$ decreases with $\mu$. However, numerical simulations reveal that GDP increases with $\mu$ for our baseline set of parameter values (see Figure 6 in Appendix G). Considering variations of $\mu$ between 0.3 and 1 to estimate the elasticity, we find that doubling $\mu$ increases GDP by $7.3 \%$ on average. To sum up, we have:

Proposition 4 (Land supply and sectors) Both the prices of land and built space decrease while all three sectors produce more when the land supply is more elastic. Furthermore, the drop in the land price is larger than the drop in the building price.

Finally, let us consider individual welfare. Since $\mathcal{E}_{\mu}\left(p_{b}\right)<0$ and $\mathcal{E}_{\mu}\left(w_{\ell}\right)>0,(6)$ implies that the unskilled are better off. As for the skilled, their welfare (6) is given by $V_{s}=\left(w_{s}-\bar{h} p_{b}\right) / p_{b}^{\gamma}$, which increases with $\mu$ because $w_{s}$ increases while $p_{b}$ decreases. In other words, the skilled are also better off because the housing price $p_{b}$ decreases with $\mu$.

In sum, an undersupply of developable land has negative effects on the whole economy, as well as on individual welfare.

\subsection{Alternative uses of land}

Until now, we have considered that land could be used without frictions for either residential, office, or production uses. This is clearly a simplification. First, land-use regulations create substantial frictions in the conversion of land between alternative uses. Second, even in the absence of such frictions, industrial land often requires to be decontaminated before it can be used for residential development. This implies that the supply of land cannot be dispatched without substantial frictions between broad competing categories.

We now consider the case where land is imperfectly substitutable between alternative uses. More precisely, industrial land can be transformed into residential land (or vice versa) only by incurring some additional cost. To keep the analysis tractable, in what follows we assume that the amount of land available for development increases with the output of the construction sector not anymore as $S=B^{\mu}$ but instead as follows:

$$
S=\left(B_{h}^{\zeta}+B_{I}^{\zeta}+B_{x}^{\zeta}\right)^{\frac{\mu}{\zeta}} .
$$

Hence, not only the total demand for land for buildings matters, but also the distribution of demand across types of uses. When $\zeta>1$ there are frictions between alternative uses, i.e., more land is required to serve the same overall demand: $\zeta \in[1, \infty)$ parametrizes the elasticity of substitution between residential and office buildings. When $\zeta=1$, land is perfectly fungible across uses and we fall back on our previous analysis. We show in Appendix F how the land rent and 
prices of buildings are modified in this setting. The rest of the model is identical to that we have analyzed before in the long run.

Figure 3: Perfectly fungible land (solid; $\zeta=1$ ) vs imperfectly fungible land (dashed; $\zeta=3$ ).

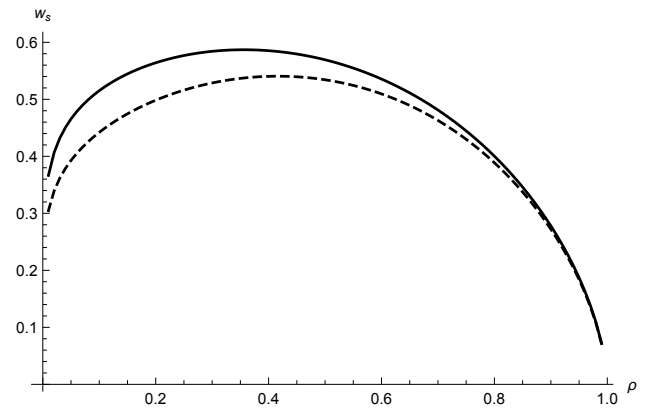

(a) skilled wages, $w_{s}$

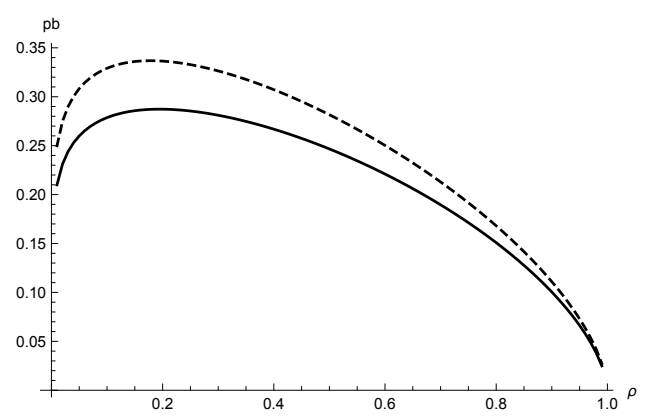

(c) building prices, $p_{b}$

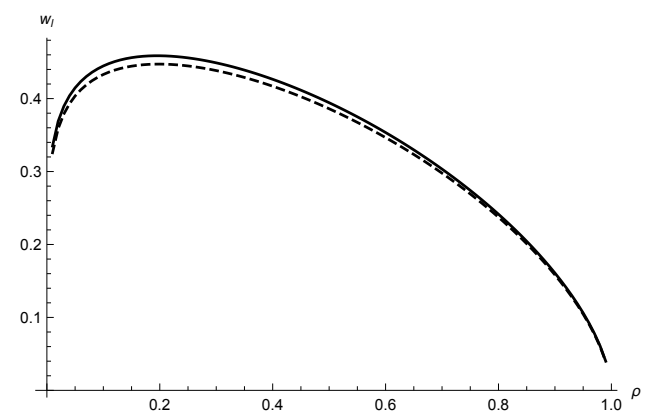

(b) unskilled wages, $w_{l}$

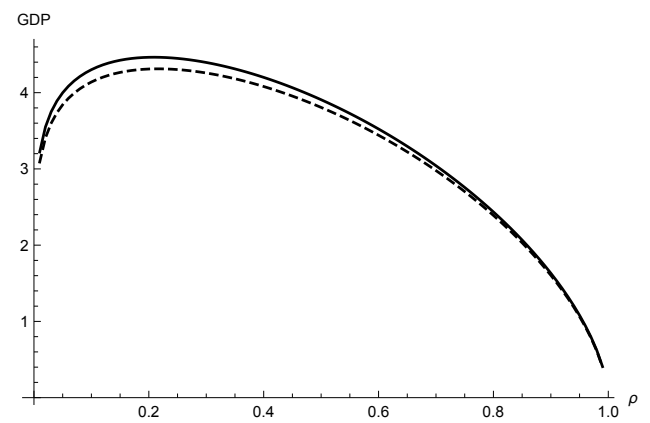

(d) Gross Domestic Product, GDP

Notes: The parameter values are set as follows: $\alpha=0.1, \beta=0.38, \delta=0.36, \gamma=0.35, \eta=1.03, \sigma=1.5, \theta=0.05, \mu=$ $0.9, L_{s}=1, L_{\ell}=7, \phi=0.2, \mu=0.9, k=0.05$, and $F=1$.

Figure 3 depicts simulation results for our baseline set of parameter values. As shown, quite naturally the price of buildings increases and wages and GDP fall as the frictions between the alternative uses of land increase. The overall effect is quite similar to that of reducing the supply elasticity of land $\mu$ as depicted in Figure 1.

\section{Equilibrium WFH rate}

Until now, we have assumed that the WFH share was exogenously given and that changes therein were due to exogenous shocks like a pandemic or technological progress. Let us now assume that firms choose noncooperatively their WFH shares prior to the game in which prices are determined. When choosing $\rho$, firms anticipate what the corresponding equilibrium prices will be. By plugging (11) into (20), we obtain the following equation:

$$
\rho=\frac{\phi \delta^{\frac{\delta}{1-\delta}}+\phi \frac{w_{s}(\rho)}{w_{\ell}(\rho)} B(\rho)^{-\frac{(1-\mu) \delta}{1-\delta}}}{\phi \delta^{\frac{\delta}{1-\delta}}+[(1-\phi) \eta+\phi] \frac{w_{s}(\rho)}{w_{\ell}(\rho)} B(\rho)^{-\frac{(1-\mu) \delta}{1-\delta}}}
$$


whose solution $\rho^{*}$ is a symmetric noncooperative equilibrium WFH rate. The left-hand side of (43) is equal to 0 at $\rho=0$ and equal to 1 at $\rho=1$. As for the right-hand side, it is positive at $\rho=0$ and smaller than 1 at $\rho=1$. The intermediate value theorem implies that (43) has at least one solution. Furthermore, the right-hand side may decrease or increase over $\left(0, \rho_{B}\right)$ because both the output $B(\rho)$ and the wage ratio increase. It, however, decreases over $\left(\rho_{B}, 1\right)$ because the wage ratio increases and $B(\rho)$ decreases with $\rho$. Since the right-hand side is positive at $\rho=0$, (43) has a unique solution independently of whether the right-hand side decreases or increases over $\left(0, \rho_{B}\right)$. Hence, there exists a unique symmetric equilibrium WFH rate. This equilibrium share minimizes firms' total costs at the equilibrium market prices and takes on values that are positive and smaller than 1.

Since both $B(\rho)$ and the wage ratio $w_{s}(\rho) / w_{\ell}(\rho)$ are independent of the technology parameter $\phi$ and the degree of agglomeration economies $\eta$, it is readily verified that $\rho^{*}$ increases with $\phi$ and decreases with $\eta$. In other words, a higher $\phi$, which corresponds to more efficient ICTs, leads firms to increase their WFH share whereas a larger $\eta$, which increases the productivity of office-workers, holds back the equilibrium WFH rate. Panel (b) of Figure 4 shows how the equilibrium WFH share varies with improvements in the ICTs.

It is worth studying how large is $\rho^{*}$. Our simulations show that, for our baseline set of parameters $(\mu=0.9, \theta=0.05, k=0.05$ and $\phi=0.2), \rho^{*}=0.266$, which is larger than the value $\rho=0.21$ where the GDP is maximized. As seen above, a larger value of $\phi$ leads to a higher value of $\rho^{*}$ : for $\phi=0.4$ we have $\rho^{*}=0.482$, which is again larger than the value $\rho=0.41$ where GDP is maximized. Thus, in these two cases, firms choose a rate of work dispersion that is larger than the one that maximizes the GDP. The intuition underlying this result is a classical one in monopolistic competition: firms disregard the effect of product diversity on productivity in the consumption good sector (recall that the choice of $\rho$ affects product diversity $M$ ). Thus, they choose a value of $\rho$ that is not optimal from a social point of view because they care about private profits (which decrease with the number of competitors) while disregarding the positive externality that a larger mass of intermediates has on the consumption sector. ${ }^{16}$

As for the land supply elasticity, its impact on $\rho^{*}$ is more complex because both $B(\rho)$ and the wage ratio depend on $\rho$ and $\mu$ through various channels. Our simulations above show that, for the baseline case with $\mu=0.9$, we have $\rho^{*}=0.266$, which is smaller than the value $\rho^{*}=0.284$ obtained for $\mu=0.7$. On the one hand, more available land (larger $\mu$ ) makes WFH less attractive from the firms' viewpoint because land scarcity is less of an issue. On the other hand, an elastic land supply makes it easier for workers to expand their housing consumption, which allows workers to save more on commuting expenditures.

The outcome of this trade-off is a priori undetermined. However, using (31), it is readily verified

\footnotetext{
${ }^{16}$ See part 1.D. in Dixit and Stiglitz (1977), who show that there is insufficient entry in a CES model with a competitive outside sector.
} 
Figure 4: Changes in $\rho^{*}$ as a function of $\mu$ (with $\phi=0.2$ ) and $\phi$ (with $\mu=0.9$ ).

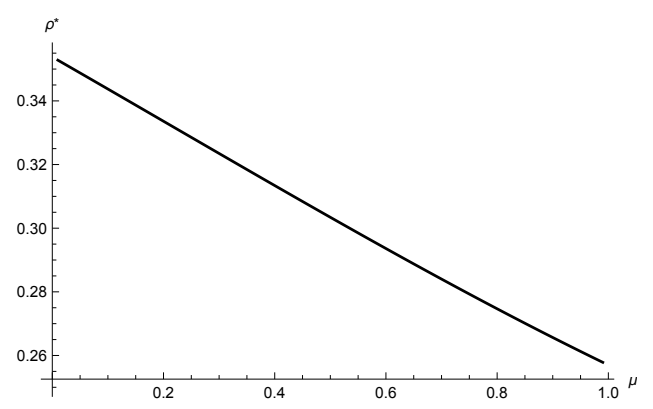

(a) equilibrium WFH and $\mu$

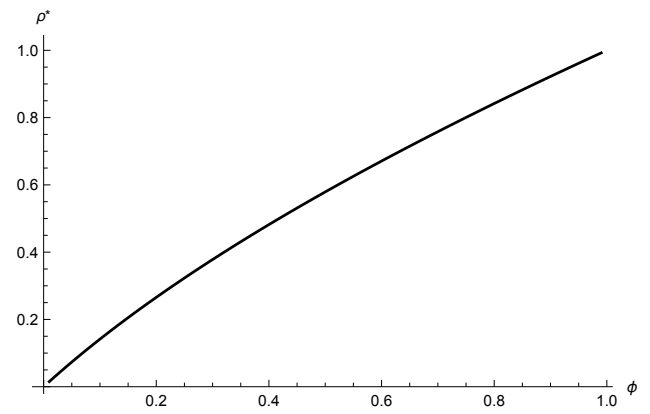

(b) equilibrium WFH and $\phi$

Notes: The parameter values are set as follows: $\alpha=0.1, \beta=0.38, \delta=0.36, \gamma=0.35, \eta=1.03, \sigma=1.5, \theta=0.05, \mu=$ $\{0.7,0.9\}, L_{s}=1, L_{\ell}=7, k=0.05, \tau=1.087$ and $F=1$.

that the denominator of the right-hand side of (43) increases with $\mu$. Hence, a higher $\mu$ leads to a lower equilibrium share $\rho^{*}$. Panel (a) of Figure 4 illustrates this finding. This suggests that cities where land-use is heavily regulated are likely to experience more work dispersion.

\section{Conclusion}

Telecommuting triggers a variety of effects that go far beyond its impact on individual workers' productivity. To study the interplay between these effects, we have developed a general equilibrium model with three sectors and two types of labor that allows us to shed new light on the main trade-offs arising in an economy where WFH is used on a relatively large scale. Our analysis shows that it is profit-maximizing for firms to implement a partial WFH strategy, that is, the working time is split between home and office. At given market prices, the equilibrium WFH share increases with the efficiency of ICTs. This suggests that telecommuting should keep rising with the development of increasingly efficient communication technologies. Yet, one should keep in mind that the equilibrium WFH share decreases with the intensity of face-to-face contacts among office-workers and other types of agglomeration economies whose existence together with their heterogeneity across industries are indisputable (Faggio et al., 2017). Furthermore, caution is needed because a significant extension of telework will affect market prices in ways that are not always easy to predict. Finally, raising the WFH share has both redistributional consequences and effects for GDP which have so far been put aside. Thus, looking only at the short-run performance of teleworking firms to predict the global impact of WFH will provide a fairly incomplete picture of how the economy will be transformed.

Furthermore, we have seen that raising the WFH share has, first, a positive and, then, a negative impact on incomes and GDP. However, labor being probably the most differentiated production 
factor, implementing a uniform share will likely generate undesirable effects. The best share varies with the occupations and the industries, as well as with workers' individual characteristics. Even though WFH has several desirable effects, e.g., the reduction of congestion and pollutant emissions associated with intensive and long commuting, our results suffice to show that WFH is not the universal panacea promoted by consulting firms and analysts.

In this paper, we have used a setting that is too stylized to work out all the effects of WFH. This leads us to mention a few important extensions that should be explored in the near future. First, our two-location framework must be extended to a multi-location space in order to understand how the structure and composition of cities will be affected by telecommuting. In particular, it is important to better understand how changes in demand and supply of housing may affect the urban footprint (sprawl) and the supply of public transportation (which may be negatively affected by sprawl and decreased demand for commuting).

Second, Moretti (2012) has argued that the launching of skilled jobs in cities is a powerful strategy to create complementary jobs for the unskilled. It is not a priori clear whether this positive effect still holds when the skilled are dispersed and work home. Understanding more fully how much of the agglomeration benefits are generated 'in the office' thus seems like an important topic. Firms' productivity depends on work arrangements, and the feasibility of the latter may differ substantially across places. This suggests that the interaction between urban form and firms' organization may strongly affect productivity, a topic that has to our knowledge been little explored in economics.

Last, it is well documented that researchers benefit from physical proximity (Kerr and RobertNicoud, 2020). For example, in a study on the spatial organization of MIT, Claudel et al. (2017, p.2) highlight "the significant role that spatial proximity still plays in collaborative knowledge creation process despite the abundance of tools for digital communication and virtual collaboration" (our emphasis). Due to the Covid-19, we have used intensively modern communication technologies to develop and write this paper. Luckily, we had already worked together before and were thus able to leverage substantial tacit knowledge about the team. Despite of this, our experience did not convince us that ICTs are (yet) a great substitute for discussions in the office or around the coffee machine.

\section{References}

[1] Adams-Prassl, A., T. Boneva, M. Golin, and C. Rauh (2020) Work that can be done from home: Evidence on variation within and across occupations and industries. IZA DP No. 13374.

[2] Allen, T.D., T.D. Golden and K.M. Shockley (2015) How effective is telecommuting? Assessing the status of our scientific findings. Psychological Science in the Public Interest 16: 
40-68.

[3] Arzaghi, M. and J.V. Henderson (2008) Networking off Madison Avenue. Review of Economic Studies 75: 1011-38.

[4] Bartik, A. W., Z. B. Cullen, E. L. Glaeser, M. Luca, and C. T. Stanton (2020) What jobs are being done at home during the Covid-19 crisis? Evidence from firm-Level Surveys. NBER Working Paper 27422.

[5] Bloom, N., J. Liang, J. Roberts, and Z.J. Ying (2015) Does working from home work? Evidence from a Chinese experiment. Quarterly Journal of Economics 130: 165-218.

[6] Bloom, N. (2020) How working from home works out. Stanford, Policy Brief.

[7] Bodenstein, M., G. Corsetti and L. Guerrieri (2020) Social distancing and supply disruptions in a pandemic. Covid Economics 19: 1-52.

[8] Brinkman, J., D. Coen-Pirani and H. Sieg (2015) Firm dynamics in an urban economy. International Economic Review 56: 1135-64.

[9] Carlino, G.A. and W.R. Kerr (2015) Agglomeration and innovation. In: G. Duranton, J.V. Henderson and W. Strange (eds.) Handbook of Regional and Urban Economics. Volume 5. Amsterdam, Elsevier, 349-404.

[10] Cheshire, P.C., C.A.L. Hilber and I. Kaplanis (2015) Land use regulation and productivityland matters: Evidence from a UK supermarket chain. Journal of Economic Geography 15: 43-73.

[11] Claudel M., E. Massaro, P. Santi, F. Murray, and C. Ratti (2017) An exploration of collaborative scientific production at MIT through spatial organization and institutional affiliation. PLoS ONE 12: 1-22.

[12] Combes, P.-P., G. Duranton and L. Gobillon (2016) The production function for housing: Evidence from France. CEPR Discussion Paper DP11669.

[13] Combes, P.-P., G. Duranton and L. Gobillon (2019) The costs of agglomeration: House and land prices in French cities. Review of Economic Studies 86: 1556-89.

[14] Combes, P-P., G. Duranton, L. Gobillon, D. Puga, and S. Roux (2012) The productivity advantages of large cities: Distinguishing agglomeration from firm selection. Econometrica 80: $2543-94$. 
[15] Couture, V. and J. Handbury (2020) Urban revival in America. Journal of Urban Economics 119: 103267

[16] Davis, M. and F. Ortalo-Magné (2011) Household expenditures, wages, rents. Review of Economic Dynamics 14: 248-61.

[17] Dingel, J. and B. Neiman (2020) How many jobs can be done at home? Journal of Public Economics 189: 104235.

[18] Dixit, A.K., and J.E. Stiglitz (1977) Monopolistic competition and optimum product diversity. American Economic Review 67(3): 297-308.

[19] Duranton, G. and D. Puga (2004) Micro-foundations of urban increasing returns: Theory. In: Handbook of Regional and Urban Economics. Volume 4, edited by J.V. Henderson and J.-F. Thisse, 2063-117. Amsterdam: Elsevier.

[20] Duranton, G. and D. Puga (2020) The economics of urban density. Journal of Economic Perspectives 34: 3-26.

[21] Edlund, L., C. Machado and M.M. Sviatschi (2015) Gentrification and the rising returns to skill. NBER Working Paper w21729.

[22] Etheridge, B., L. Tang and Y. Wang (2020) Worker productivity during lockdown and working from home: Evidence from self-reports. Covid Economics 52: 118-151.

[23] Faggio, G., O. Silva and W.C. Strange (2017) Heterogeneous agglomeration. Review of Economics and Statistics 99: 80-94.

[24] Gajendran, R.S. and D.A. Harrison (2007) The good, the bad, and the unknown about telecommuting: Meta-analysis of psychological mediators and individual consequences. Journal of Applied Psychology 92: 1524-41.

[25] Glaeser, E. and J. Gyourko (2018) The economic implications of housing supply. Journal of Economic Perspectives 32: 3-30.

[26] Glaeser, E., J. Gyourko and R. Saks (2005) Why is Manhattan so expensive? Regulation and the rise in housing prices. Journal of Law and Economics XLVIII: 331-369.

[27] Golden, T.D. (2007) Co-workers who telework and the impact on those in the office: Understanding the implications of virtual work for co-worker satisfaction and turnover intentions. Human Relations 60: 1641-67. 
[28] Golden, T.D. and J.F. Veiga (2005) The impact of extent of telecommuting on job satisfaction: Resolving inconsistent findings. Journal of Management 31: 301-18.

[29] Gottlieb, C. J. Grobovček and M. Poschke (2020) Working from home across countries. Covid Economics 8: 71-91.

[30] Hilber, C.A.L. and W. Vermeulen (2014) The impact of supply constraints on house prices in England. Economic Journal 126: 358-405.

[31] Hsieh, C.-T. and E. Moretti (2019) Housing constraints and spatial misallocation. American Economic Journal: Macroeconomics 11: 1-39.

[32] Kahneman, D., A.B. Krueger, D.A. Schkade, N. Schwarz, and A.A. Stone (2004) A survey method for characterizing daily life experience: The day reconstruction method. Science 306: $1776-80$.

[33] Karadi, P. and M. Koren (2017) Cattle, steaks and restaurants: Development accounting when space matters. Memo, Central European University.

[34] Kerr, W.R. and F. Robert-Nicoud (2020) Tech clusters. Journal of Economic Perspectives 34: 50-76.

[35] Koren, M. and R. Peto (2020) Business disruptions from social distancing. Covid Economics 2: $13-31$.

[36] Koster, P.R. and H.R.A. Koster (2015) Commuters' preferences for fast and reliable travel: A semiparametric estimation approach. Transportation Research Part B: Methodological 81: 289-301.

[37] Krantz-Kent, R.M. (2019) Where did workers perform their jobs in the early 21st century? Monthly Labor Review. U.S. Bureau of Labor Statistics, July 2019.

[38] Liu, C.H., S.S. Rosenthal and W.C. Strange (2018) The vertical city: Rent gradients, spatial structure, and agglomeration economies. Journal of Urban Economics 106: 101-22.

[39] Mas, A. and A. Pallais (2017) Valuing alternative work arrangements. American Economic Review 107: 3722-59.

[40] Mas, A. and A. Pallais (2020) Alternative work arrangements. Annual Review of Economics 12: 631-58.

[41] Mattana, E., V. Smeets and F. Warzynski (2020) Changing skill structure and COVID-19. Covid Economics 45: 1-30. 
[42] Miranda-Pinto, J. (2020) Production network structure, service share, and aggregate volatility. Review of Economic Dynamics, available online 9 July 2020.

[43] Miranda-Pinto, J. and E.R. Young (2020) Flexibility and frictions in multisector models. Memo, University of Virginia.

[44] Monte, F., S.J. Redding and E. Rossi-Hansberg (2018) Commuting, migration, and local employment elasticities. American Economic Review 108: 3855-90.

[45] Moretti, E. (2012) The New Geography of Jobs. Boston: Houghton Mifflin Harcourt.

[46] Morikawa, M. (2020) Productivity of working from home during the COVID-19 pandemic: Evidence from an employee survey. Covid Economics 49: 123-139.

[47] OECD (2020) Productivity gains from teleworking in the post COVID-19 era: How can public policies make it happen?

[48] Redding, S.J. and M.A. Turner (2015) Transportation costs and the spatial organization of economic activity. In: Handbook of Urban and Regional Economics, Volume 5, edited by G. Duranton, J.V. Henderson, and W.C. Strange, 1339-98. Amsterdam: Elsevier

[49] Rhee, H.-J. (2008) Home-based telecommuting and commuting behavior. Journal of Urban Economics 63: 198-216.

[50] Rockmann, K.W. and M.G. Pratt (2015) Contagious offsite work and the lonely office: The unintended consequences of distributed work. Academy of Management Discoveries 1: 150-64.

[51] Rosenthal, S.S. and W.C. Strange (2020) How close is close? The spatial reach of agglomeration economies. Journal of Economic Perspectives 34: 27-49.

[52] Safirova, E. (2002) Telecommuting, traffic congestion, and agglomeration: A general equilibrium model. Journal of Urban Economics 52: 26-52.

[53] Saiz, A. (2010) The geographic determinants of housing supply. Quarterly Journal of Economics 125: 1253-96.

[54] Small, K.A. (2012) Valuation of travel time. Economics of Transportation 1: 2-14.

[55] Spreitzer, G. M., L. Cameron and L. Garrett (2017) Alternative work arrangements: Two images of the new world of work. Annual Review of Organizational Psychology and Organizational Behavior 4: 473-99.

[56] Taskin, L. and F. Bridou (2010) Telework: A challenge to knowledge transfer in organizations. International Journal of Human Resource Management 21: 2503-20. 
[57] van Ommeren, J.N. and E. Gutiérrez-i-Puigarnau (2011) Are workers with a long commute less productive? An empirical analysis of absenteeism. Regional Science and Urban Economics 41: $1-8$.

[58] Zenou, Y. (2009) Urban Labor Economics. Cambridge: Cambridge University Press.

\section{Appendix}

\section{A. The skill premium}

Taking the elasticity of (31) with respect to $L_{\ell}$ yields

$$
\mathcal{E}_{L_{\ell}}(B)=(1-\delta) \frac{\delta^{\frac{-\delta}{1-\delta}} \frac{\gamma+\alpha \Upsilon(1-\gamma)}{\Psi} L_{\ell}}{(1-\delta \mu) B^{\frac{1-\delta \mu}{1-\delta}}-(1-\mu) \delta(\bar{h}+1-\rho) \Omega L_{s} B^{\frac{(1-\mu) \delta}{1-\delta}}} .
$$

Using (31), this becomes:

$$
\mathcal{E}_{L_{\ell}}(B)=\left(\frac{1-\delta}{1-\delta \mu}\right) \frac{\delta^{\frac{-\delta}{1-\delta}} \frac{\gamma+\alpha \Upsilon(1-\gamma)}{\Psi} L_{\ell}}{\delta^{\frac{-\delta}{1-\delta}} \frac{\gamma+\alpha \Upsilon(1-\gamma)}{\Psi} L_{\ell}+(1-\delta)(\bar{h}+1-\rho) \Omega L_{s} B^{\frac{(1-\mu) \delta}{1-\delta}}} .
$$

Clearly, we have

$$
\mathcal{E}_{L_{\ell}}(B)<\frac{1-\delta}{1-\delta \mu}<1
$$

Hence, the second term on the right-hand side of (33) increases less than proportionate with $L_{\ell}$. Since the first term on the right-hand side of (33) increases proportionally with $L_{\ell}$, there exists a number of unskilled workers $\bar{L}_{\ell}$ such that the inequality $w_{s} / w_{\ell}>1$ holds for any $L_{\ell}>\bar{L}_{\ell}$.

\section{B. The wage ratio}

Equation (33) may be rewritten as follows:

$$
\frac{w_{s}}{w_{\ell}}=\frac{1-(1-\delta) \gamma}{(1-\delta) \gamma+\Gamma} \frac{L_{\ell}}{L_{s}}-\frac{(1-\delta)(1-\gamma) \delta^{\frac{\delta}{1-\delta}}}{(1-\delta) \gamma+\Gamma}(\bar{h}+1-\rho) B^{\frac{(1-\mu) \delta}{1-\delta}}-\frac{(\Gamma+\gamma) \delta^{\frac{\delta}{1-\delta}}}{(1-\delta) \gamma+\Gamma}(1-\rho) B^{\frac{(1-\mu) \delta}{1-\delta}}
$$

As implied by (31), the second term on the right-hand side of $($ C.1 $),(\bar{h}+1-\rho) B^{\frac{(1-\mu) \delta}{1-\delta}}$ varies in the same way as $B$, that is, it decreases for $\rho>\rho_{B}$. The last term on the right hand side also decreases because both $(1-\rho)$ and $B^{\frac{(1-\mu) \delta}{1-\delta}}$ are decreasing functions of $\rho$. Therefore, the right hand 
side of (44) increases with the WFH share:

$$
\mathcal{E}_{\rho}\left(\frac{w_{s}}{w_{\ell}}\right)>0
$$

\section{The skilled welfare}

Using (11) and (33), we have:

$$
V_{s}=\frac{w_{s}-p_{b} \bar{h}}{p_{b}^{\gamma}}=\frac{\frac{1-(1-\delta) \gamma}{(1-\delta) \gamma+\Gamma} \frac{L_{\ell}}{L_{s}}-\frac{(\Gamma+1-\delta) \delta^{\frac{\delta}{1-\delta}}}{(1-\delta) \gamma+\Gamma}(\bar{h}+1-\rho) B^{\frac{(1-\mu) \delta}{1-\delta}}}{\delta^{\frac{\delta \gamma}{1-\delta}} B^{\frac{(1-\mu) \delta \gamma}{1-\delta}}} w_{\ell}^{1-\gamma}
$$

As implied by (31), the second term on the right-hand side in the numerator, $(\bar{h}+1-\rho) B^{\frac{(1-\mu) \delta}{1-\delta}}$, varies in the same way as $B$. Therefore, the ratio increases for $\rho>\rho_{B}$. However, $w_{\ell}$ is bell-shaped with $\mathcal{E}_{\rho}\left(w_{\ell}\right) \rightarrow-\infty$ when $\rho \rightarrow 1$. Hence, there exists a unique threshold $\rho_{V_{s}}$ such that $\mathcal{E}_{\rho}\left(V_{s}\right)>0$ if $\rho<\rho_{V_{s}}$ while $\mathcal{E}_{\rho}\left(V_{s}\right)<0$ otherwise.

\section{Existence of an equilibrium WFH share}

Whether the right-hand side of (43) increases or decreases depends on the behavior of $\left(w_{s} / w_{\ell}\right) B^{-(1-\mu) \delta /(1-\delta)}$. The elasticity of this function is given by

$$
\mathcal{E}_{\rho}\left(\frac{w_{s}}{w_{\ell}} B^{\frac{-(1-\mu) \delta}{1-\delta}}\right)=\mathcal{E}_{\rho}\left(\frac{w_{s}}{w_{\ell}}\right)-(1-\mu) \frac{\delta}{1-\delta} \mathcal{E}_{\rho}(B)
$$

Using (33), (34), and (C.1) yields:

$$
\begin{aligned}
\Psi \frac{w_{s}}{w_{\ell}} \mathcal{E}_{\rho}\left(\frac{w_{s}}{w_{\ell}} B^{\frac{-(1-\mu) \delta}{1-\delta}}\right)= & \delta^{\frac{\delta}{1-\delta}}\left[(1-\delta) \rho+\theta(\Psi-(1-\delta)) k \rho^{\theta}\right] B^{\frac{-(1-\mu) \delta}{1-\delta}} \\
& -(1-\Psi) \frac{L_{\ell}}{L_{s}} \frac{(1-\mu) \delta\left(\theta k \rho^{\theta}-\rho\right) \Omega L_{s}}{(1-\delta \mu) B-(1-\mu) \delta\left(k \rho^{\theta}-\rho+1\right) \Omega L_{s}}
\end{aligned}
$$

Since the right-hand side increases with $B$, we obtain a lower bound by setting $B=1$ :

$$
\begin{aligned}
\Psi \frac{w_{s}}{w_{\ell}} \mathcal{E}_{\rho}\left(\frac{w_{s}}{w_{\ell}} B^{\frac{-(1-\mu) \delta}{1-\delta}}\right)> & \delta^{\frac{\delta}{1-\delta}}\left[(1-\delta) \rho+\theta(\Psi-(1-\delta)) k \rho^{\theta}\right] \\
& -(1-\Psi) \frac{L_{\ell}}{L_{s}} \frac{(1-\mu) \delta\left(\theta k \rho^{\theta}-\rho\right) \Omega L_{s}}{1-\delta \mu-(1-\mu) \delta\left(k \rho^{\theta}-\rho+1\right) \Omega L_{s}} .
\end{aligned}
$$

Furthermore, the right-hand side of (E.1) increases with $\mu$. Therefore, we obtain another lower 
bound for $\mu=0$ :

$$
\Psi \frac{w_{s}}{w_{\ell}} \mathcal{E}_{\rho}\left(\frac{w_{s}}{w_{\ell}} B^{\frac{-(1-\mu) \delta}{1-\delta}}\right)>\delta^{\frac{\delta}{1-\delta}}\left[(1-\delta) \rho+\theta(\Psi-(1-\delta)) k \rho^{\theta}\right]-(1-\Psi) \frac{L_{\ell}}{L_{s}} \frac{\delta\left(\theta k \rho^{\theta}-\rho\right) \Omega L_{s}}{1-\delta\left(k \rho^{\theta}-\rho+1\right) \Omega L_{s}} .
$$

Finally, plugging the empirically relevant parameter values and $\theta=0.1$ into the right hand-side of this expression shows that this term is positive for all $\rho \in[0,1]$. Hence,

$$
\mathcal{E}_{\rho}\left(\frac{w_{s}}{w_{\ell}} B^{\frac{-(1-\mu) \delta}{1-\delta}}\right)>0
$$

\section{E. The buildings output}

It follows from $(31)$ that $B>1$ if and only if $F(1)=1 \leq G(1)$ for all $\rho \in[0,1]$. This inequality is equivalent to

$$
1 \leq\left(k \rho^{\theta}+1-\rho\right) \Omega L_{s}+\delta^{\frac{-\delta}{1-\delta}} \frac{\gamma+\alpha \Upsilon(1-\gamma)}{\Psi} L_{\ell},
$$

which holds for all $\rho \in[0,1]$ if it is satisfied when $\rho^{\theta}+1-\rho$ is minimized, that is, when $\rho=0$ or $\rho=1$. Therefore, $F(1) \leq G(1)$ if

$$
1 \leq \Omega L_{s}+\delta^{\frac{-\delta}{1-\delta}} \frac{\gamma+\alpha \Upsilon(1-\gamma)}{\Psi} L_{\ell}
$$

holds. This inequality is always satisfied when $L_{\ell}$ is sufficiently large.

\section{F. Imperfect substitutability between residential and office buildings}

The land rent is determined by the land market clearing condition:

$$
B_{o} \frac{\partial c_{b}^{o}}{\partial r}+B_{p} \frac{\partial c_{b}^{p}}{\partial r}+B_{h} \frac{\partial c_{b}^{h}}{\partial r}=S
$$

where $\partial c_{b}^{i} / \partial r$ is the amount of land required to produce one unit of building $i=o, p, h$. The marginal production cost for each type of building ( $o=$ office, $p=$ plants, $h=$ housing) equals

$$
c_{b}^{o}=r^{\delta} w_{\ell}^{1-\delta}, \quad c_{b}^{p}=r^{\delta} w_{\ell}^{1-\delta}, \quad c_{b}^{h}=r^{\delta} w_{\ell}^{1-\delta}
$$

Equalizing these two yields $\delta\left(w_{\ell} / r\right)^{1-\delta}\left(B_{p}+B_{o}+B_{h}\right)=\left(B_{h}^{\zeta}+B_{I}^{\zeta}+B_{x}^{\zeta}\right)^{\frac{\mu}{\zeta}}$, which can be solved for the equilibrium land rent as a function of the construction sector's output:

$$
r=\left[\frac{\delta w_{\ell}^{1-\delta}\left(B_{p}+B_{o}+B_{h}\right)}{\left(B_{h}^{\zeta}+B_{p}^{\zeta}+B_{o}^{\zeta}\right)^{\frac{\mu}{\zeta}}}\right]^{\frac{1}{1-\delta}}
$$


Perfect competition in the construction sector implies that $p_{b}^{i}=p_{b}$ equals marginal cost:

$$
p_{b}=w_{\ell}^{1-\delta} r^{\delta}=\delta^{\frac{\delta}{1-\delta}} w_{\ell}\left[\frac{B_{p}+B_{o}+B_{h}}{\left(B_{h}^{\zeta}+B_{p}^{\zeta}+B_{o}^{\zeta}\right)^{\frac{\mu}{\zeta}}}\right]^{\frac{\delta}{1-\delta}} .
$$

Price is the same for each type of building because costs are the same.

Finally, we need market clearing of the three buildings markets:

$$
\begin{gathered}
B_{h}=\gamma \frac{w_{\ell} L_{\ell}+w_{s} L_{s}}{p_{b}}+(1-\gamma) \bar{h} L_{s}, \\
B_{o}=(1-\rho) L_{s}, \\
B_{p}=\frac{\alpha Y}{p_{b}}+\alpha \beta \frac{\sigma-1}{\sigma} \frac{Y}{p_{b}} .
\end{gathered}
$$

Last, $A L R$ is modified as follows:

$$
A L R=r S=\left[\frac{\delta w_{\ell}^{1-\delta}\left(B_{p}+B_{o}+B_{h}\right)}{\left(B_{h}^{\zeta}+B_{p}^{\zeta}+B_{o}^{\zeta}\right)^{\frac{\mu}{\zeta}}}\right]^{\frac{1}{1-\delta}}\left(B_{h}^{\zeta}+B_{p}^{\zeta}+B_{o}^{\zeta}\right)^{\frac{\mu}{\zeta}}
$$




\section{G. Additional figures}

Figure 5: Equilibrium outcomes as a function of the WFH share $\rho$ for less good communication technology $\phi=0.4$ (we depict $\mu=0.9$, solid curve; $\mu=0.7$, dashed curve).

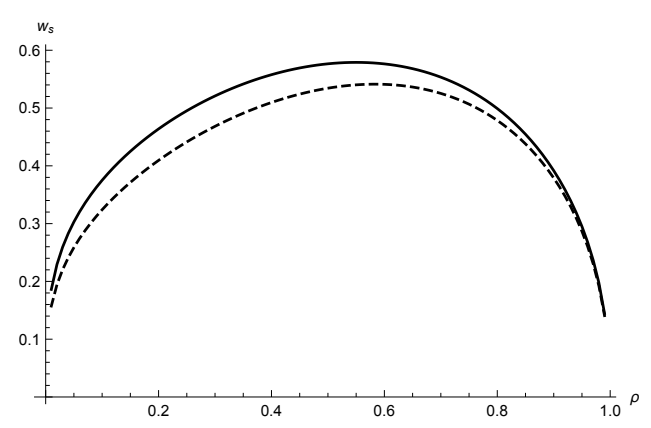

(a) skilled income, $w_{s}$

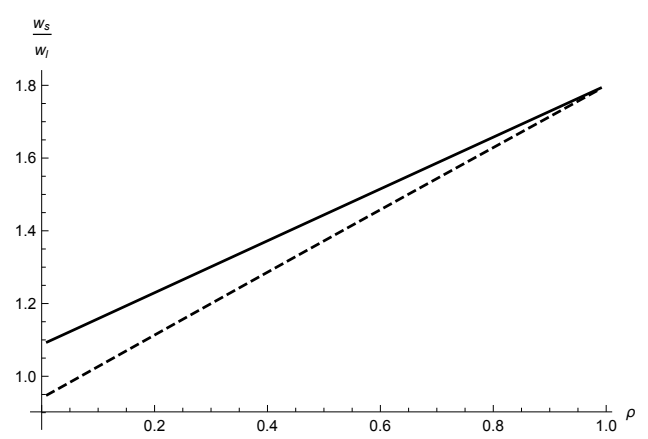

(c) relative income, $w_{s} / w_{\ell}$

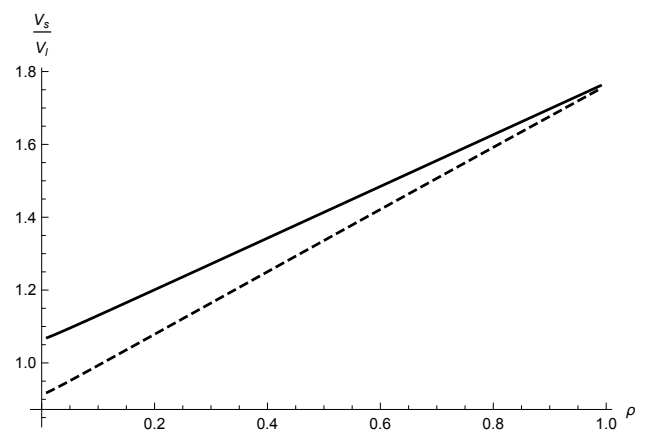

(e) relative welfare, $V_{s} / V_{\ell}$

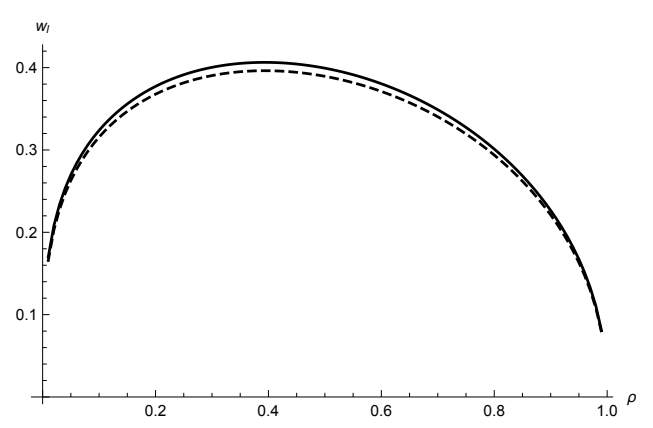

(b) unskilled income, $w_{\ell}$

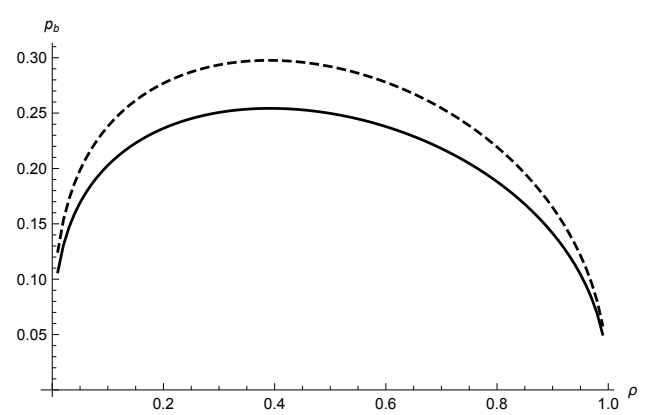

(d) building prices, $p_{b}$

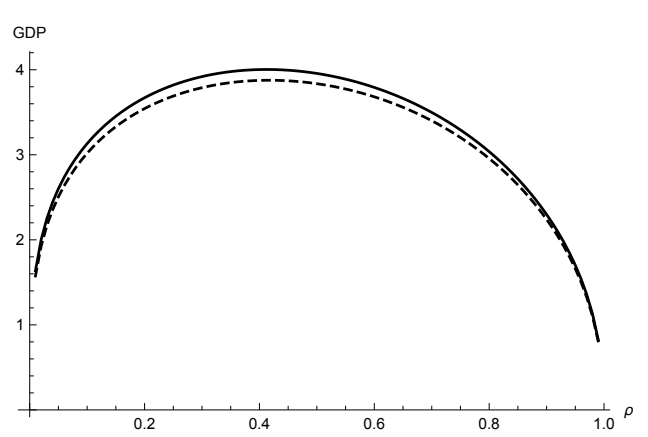

(f) Gross Domestic Product, GDP

Notes: The parameter values are set as follows: $\alpha=0.1, \beta=0.35, \delta=0.36, \gamma=0.35, \eta=1.03, \sigma=$ $4.7, \theta=0.05, \mu=\{0.7,0.9\}, L_{s}=5, L_{\ell}=200, \phi=0.4, k=0.05$, and $F=1$. 
Figure 6: GDP as a function of the land supply elasticity $\mu$.

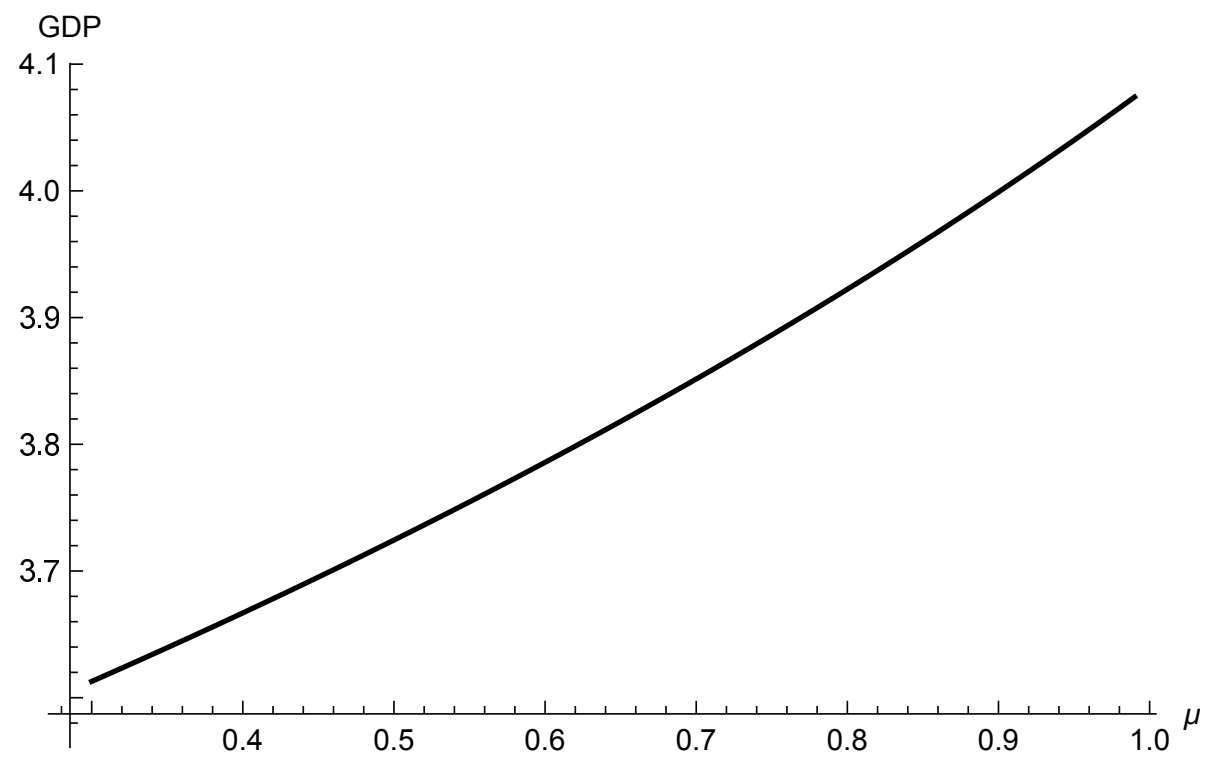

Notes: The parameter values are set as follows: $\alpha=0.1, \beta=0.35, \delta=0.36, \gamma=0.35, \eta=1.03, \sigma=4.7, \theta=$ $0.05, \mu=\{0.7,0.9\}, L_{s}=5, L_{\ell}=200, \phi=0.4, k=0.05$, and $F=1$. 